\title{
6. Die gruppenspezifische Arbeitsmarktpolitik
}

\section{Flüchtlinge und Vertriebene}

Die arbeitsmarktpolitischen Programme zugunsten der Flüchtlinge und Vertriebenen waren in der SBZ von Anfang an sehr stark abhängig vom Vertreibungsverlauf. Frühzeitig setzte sich bei den neu aufgebauten deutschen Verwaltungen die Erkenntnis durch, daß eine geordnete Ansiedlung der Flüchtlinge und Vertriebenen nahezu undurchführbar war. Dies galt im übrigen nicht nur für die sowjetische, sondern auch für die drei westlichen Besatzungszonen. Bereits vor dem Ende des Zweiten Weltkrieges war das Gebiet der späteren SBZ durch die massenhafte Flucht Hunderttausender vor der heranrückenden Roten Armee überschwemmt worden. Noch vor der Unterzeichnung der bedingungslosen Kapitulation begannen die "wilden“ Vertreibungen aus dem ostmitteleuropäischen Raum. Die alliierten Siegermächte versuchten auf der Konferenz in Potsdam im Sommer 1945 diese unkontrollierte Bevölkerungsverschiebung gen Westen zu ordnen und statt dessen eine geregelte „Umsiedlung“ durchzuführen, soweit dies überhaupt möglich war1. Der Alliierte Kontrollrat verabschiedete am 21. November 1945 einen „Umsiedlungsplan“ 2 , der von einer deutschen Restbevölkerung in den ehemals deutschen Ostgebieten und Österreich von etwa 6,65 Millionen ausging. Von dieser Gesamtgruppe sollten 2,75 Millionen in der SBZ, 2,25 Millionen in der amerikanischen, 1,5 Millionen in der britischen und 150000 in der französischen Zone aufgenommen werden ${ }^{3}$. Der Plan blieb zunächst jedoch nur Makulatur, da sich erst ab 1946 die Praxis der geregelten Transporte mit der Eisenbahn langsam durchsetzen ließ4.

Auf seiten der SMAD begannen die Planungen zur Aufnahme und Verteilung der "Umsiedler" in der SBZ vergleichsweise spät. Erst im Oktober 1945 wurde beispielsweise der systematische Aufbau eines Netzes von Aufnahmelagern in Angriff genommen ${ }^{5}$. Die sowjetische Besatzungsverwaltung beauftragte die neu errichteten deutschen Verwaltungen damit, an den östlichen Grenzen der SBZ zwölf Hauptlager aufzubauen, in denen die „Umsiedler" registriert und nach der strapaziösen Flucht vor allem medizinisch versorgt werden sollten. Von dort war dann eine Weiterführung ins Landesinnere vorgesehen. In den Lagern herrschten anfangs katastrophale Zustände: So war die Versorgung mit Lebensmitteln äußerst knapp und die Unterbringungsmöglichkeiten schlecht, so daß sich Krankheiten rasch ausbreiten konnten. Berichte der lokalen Behörden über Seuchen in den Lagern sind gerade in den Jahren 1945/46 sehr zahlreich 6 . In der Regel dauerte

1 Vgl. Benz, Potsdam 1945, S. 110; Henke, Der Weg nach Potsdam, S. 81; Foschepoth, Die Westmächte, S. 99 f. Den folgenden Abschnitt (S. 207-225) habe ich mit einigen Veränderungen bereits an anderer Stelle publiziert. Vgl. Hoffmann, Vertriebenenintegration durch Arbeitsmarktlenkung?, S. $174-192$.

2 Zank, Wirtschaft und Arbeit, S. 142.

3 Zu den Zahlen: Foschepoth, Die Westmächte, S. 100.

+ Vgl. ebenda, S. $101 \mathrm{f}$.

5 Vgl. Zank, Wirtschaft und Arbeit, S. 142.

6 BAB, DQ 2/3370, Bl. 316-324, hier Bl. 317, Protokoll über die Sitzung der ZVAS mit Vertretern der Provinzialverwaltungen von Brandenburg und Sachsen, den Landesverwaltungen Thüringen und Mecklenburg sowie der Stadtverwaltung von Berlin. 
außerdem die zeitliche Unterbringung der „Umsiedler" in den Aufnahmelagern zu lange ${ }^{7}$ und war ein Zeichen dafür, daß oftmals kein geeigneter Aufenthaltsort gefunden werden konnte. Die ZVU8 schob dabei den lokalen Behörden, die für die Leitung und Kontrolle der Lager zuständig waren, die Hauptschuld zu.

Auch die endgültige Verteilung der "Umsiedler“ erfolgte in der SBZ alles andere als geordnet. Zwar lag bereits am 19. Juli 1945 ein Befehl von Marschall Schukow zur regionalen Verteilung vor', dessen Realisierung aber vor Ort, d.h. in den Städten und Gemeinden, auf zunächst ungeahnte Schwierigkeiten und Widerstände stieß. Dem sowjetischen Befehl zufolge sollten sämtliche Zuwanderer aus den Ostgebieten nördlich der Warthe nach Mecklenburg, die aus den Gebieten südlich der Warthe und östlich der Oder in vier Kreise des östlichen und südöstlichen Brandenburg weitergeleitet werden ${ }^{10}$. Für die Vertriebenen aus der Tschechoslowakei und Jugoslawien war das Gebiet um Torgau und in der Lausitz bestimmt worden. Deutlich erkennbar war das Bestreben der SMAD, den Vertriebenenstrom in die dünn besiedelten Räume der SBZ zu lenken, und zwar unabhängig von der jeweiligen Arbeitsmarktlage. Offenbar hatte die SMAD in den ersten Monaten nach Kriegsende eine völlig unzureichende Vorstellung vom Ausmaß und Tempo der Vertreibung. Nur so läßt sich erklären, warum erst im Herbst mit dem Aufbau der Aufnahmelager begonnen wurde und wieso nicht schon vorher Überlegungen zur Lösung des Aufnahmeproblems angestellt worden waren.

Die Kanalisierung des Vertriebenenstroms ließ sich nur schwer durchführen und hing oftmals von der Mitarbeit der lokalen Behörden ab, welche die „Umsiedler" in benachbarte Kreise abschieben konnten. Besonders markant ist das Beispiel der sächsischen Landesregierung, die bereits im Juli 1945 die Anweisung gab, sämtliche Neuankömmlinge nach Mecklenburg weiterzuleiten ${ }^{11}$. Daraufhin ordnete die SMAD zwei Monate später einen allgemeinen Stopp der Wanderungsbewegung in der SBZ an. Die Anweisung der sowjetischen Besatzungsmacht richtete sich jedoch nicht nur gegen das eigenmächtige Handeln einzelner Landesregierungen, sondern auch gegen das planlose Umherziehen der „Umsiedler“, das die Anstrengungen zur geregelten Ansiedlung zunichte machte. Zusammenfassend läßt sich für diese frühe Phase, also bis zum Jahreswechsel 1945/46 feststellen, daß nur eine unzulängliche Aufnahmeplanung existierte. Erst danach nahm die „Umsiedler“-Politik geordnetere Züge an. $\mathrm{Da}$ die Behörden bei der provisorischen Volkszählung am 1. Dezember 1945 knapp 2,5 Millionen Vertriebene (ohne Kinder unter fünf Jahren) zählten, war bereits weit mehr als die Hälfte der Zuwanderung in der ersten Phase erfolgt und zum großen Teil planlos verteilt worden. Auch die Volkszählung im Oktober 1946, bei der 3,5 Millionen „Umsiedler" registriert wurden, zeigt, daß die anfangs angestrebte Ansiedlung nach dem Herkunftsgebiet gescheitert war. Die Landsmannschaften waren, von weni-

7 Das wurde etwa auf einer Konferenz von Vertretern der „Umsiedler" aus den Ländern und Provinzen in Berlin am 14.6. 1946 allgemein beklagt, in: BAB, DO 2/4, Bl. 100.

8 Vgl. zu Entstehung und Entwicklung der ZVU: Schwartz, Zwischen Zusammenbruch und Stalinisierung. Zur Abhängigkeit der "Umsiedler“-Politik von personellen Netzwerken: ders., Apparate und Kurswechsel.

9 Vgl. Zank, Wirtschaft und Arbeit, S. 143.

10 Vgl. Just, Die Integration der Umsiedler, S. 146.

1 Ebenda. Dies, Zur Lösung des Umsiedlerproblems, S. 975. 
gen Ausnahmen abgesehen, über die ganze SBZ verteilt. Außerdem wird deutlich, $\mathrm{da} ß$ die Verteilung der Vertriebenen besonders stark in den dünn besiedelten $\mathrm{Ge}$ bieten erfolgt war. Nach Berechnungen von Wolfgang Zank waren sogar 86 Prozent in Landkreisen angesiedelt worden ${ }^{12}$. Relativ zur Wohnbevölkerung war der Zuwandereranteil auf dem Land etwa doppelt so hoch wie in den Städten, in Sachsen statistisch gesehen sogar fast dreimal so hoch. Hierfür dürften sicherlich die katastrophale Lage in den ausgebombten Großstädten und die vergleichsweise bessere Versorgung mit Lebensmitteln auf dem Lande eine ausschlaggebende Rolle gespielt haben.

Die Verteilung der Vertriebenen auf die Länder und Provinzen der SBZ erfolgte höchst ungleichgewichtig und unterstreicht nochmals das Zielvorhaben der Besatzungsmacht sowie der deutschen Stellen, die Neuankömmlinge auf dem Land anzusiedeln. Nach einer statistischen Erhebung der ZVU über die Verteilung der „Umsiedler" mit dem Stichdatum vom 31. Dezember 1946 hatten Mecklenburg und Sachsen-Anhalt die meisten Zuwanderer aufgenommen, nämlich 980773 bzw. 961733 . Sachsen lag mit 781455 an mittlerer Position; dagegen wurden in Brandenburg und Thüringen 580571 bzw. 607390 „Umsiedler“ gezählt ${ }^{13}$. Aufschlußreich sind die prozentualen Angaben, also der Vertriebenenanteil an der Gesamtbevölkerung. Demzufolge war Mecklenburg mit weitem Abstand am stärksten belastet: 45,7 Prozent der dortigen Wohnbevölkerung waren Vertriebene. Es folgten Brandenburg, Sachsen-Anhalt und Thüringen mit einem Anteil zwischen 20,5 und 22,8 Prozent. Im bereits zuvor stärker besiedelten Sachsen machten die Zuwanderer nur 13,9 Prozent aus.

Angesichts der in den ersten Nachkriegsjahren nur geringen Unterstützung durch die öffentlichen Haushalte in Form von Krediten, Zuteilung von Sachmitteln etc., auf die an dieser Stelle nicht weiter eingegangen werden kann, war für die "Umsiedler" die Erlangung eines Arbeitsplatzes von essentieller Bedeutung. Die berufliche Vermittlung von Flüchtlingen und Vertriebenen wurde vor allem dadurch behindert, daß es den Arbeitsämtern bis Anfang 1947 nicht gelang, eine Registrierung der Neuankömmlinge nach Berufen vorzunehmen. Hintergrund dafür bildete der bereits mehrfach erwähnte Befehl Nr. 3 des Alliierten Kontrollrates vom 17. Januar 1946. Es hatte in der SBZ schon zuvor entsprechende Anweisungen der sowjetischen Besatzungsmacht gegeben, so z.B. der SMAD-Befehl Nr. 65 vom 15. September 1945, der die Wiedereinführung des Arbeitsbuches bedeutete.

Die ZVU hatte zwar in einem Rundschreiben im Oktober 1945 angekündigt, ein Fragebogen zur Registrierung der arbeitsfähigen "Umsiedler" sei geplant und würde den nachgeordneten Verwaltungseinheiten weitergeleitet werden ${ }^{14}$. $\mathrm{Da}$ die Registrierung nur von den Arbeitsämtern übernommen werden konnte - die ZVU verfügte auf der lokalen Ebene über eine personell nur schwache Verwaltungseinheit - war eine enge Zusammenarbeit mit der ZVAS erforderlich, der wiederum die Arbeitsämter unterstanden. Diese Kooperation zwischen den beiden Zentral-

12 Zank, Wirtschaft und Arbeit, S. 144.

$13 \mathrm{BAB}, \mathrm{DO} 2 / 13, \mathrm{Bl}$. 43. Zusätzlich zu den Vertriebenenzahlen enthält die Statistik auch Zahlenangaben zur Gruppe der Evakuierten, die insgesamt 704118 Personen umfaßte.

14 Zank, Wirtschaft und Arbeit, S. 148. 
verwaltungen scheint von Anfang an belastet gewesen zu sein. So beschwerte sich die Führung der ZVAS Ende November 1945 darüber, daß ein enger Mitarbeiter des ZVU-Präsidiums, Georg Chwalczyk, die Herausgabe statistischen Materials verweigert habe ${ }^{15}$. Dieses sei aber als ergänzendes Material notwendig, um die „berufliche Seßhaftmachung der Umsiedler" sicherstellen zu können. Der in der Abteilung Statistik tätige Chwalczyk mußte knapp eine Woche später einlenken und erklären, daß der ZVAS ein „Überblick über die bisher aufgenommenen Umsiedler" gegeben werden müsse ${ }^{16}$. Es dauerte dennoch ein Jahr, bis die ZVU und die ZVAS am 7. November 1946 gemeinsam eine entsprechende Anweisung zur „Wiedereingliederung der Umsiedler und Heimkehrer in den Produktionsprozeß" erließen ${ }^{17}$. An der redaktionellen Fertigstellung wirkten offensichtlich einzelne SMAD-Abteilungen mit ${ }^{18}$. Laut Anweisung war es die Aufgabe des Arbeitsamtes, das für das jeweilige Aufnahmelager zuständig war, die „Umsiedler“ innerhalb von 48 Stunden nach Berufen ${ }^{19}$ zu registrieren. Das Ergebnis sollte dann telefonisch oder per Kurier dem Landesarbeitsamt mitgeteilt werden. Dieses wiederum konnte dann einen Aufnahmeort für die einzelnen Vertriebenen festlegen. Fachkräfte, die innerhalb des Landes bzw. der Provinz nicht untergebracht werden konnten, waren der DVAS zu melden, die dann in Absprache mit der ZVU ein neues Aufnahmegebiet festzulegen hatte. Damit wurde eine systematische Registrierung erst in Angriff genommen, als der Großteil der Vertriebenen bereits verteilt und untergebracht war. Darüber hinaus muß für die Umsetzung der Anordnung eine zeitliche Verzögerung in Rechnung gestellt werden.

Nur in wenigen Fällen, in denen sich beispielsweise Großbetriebe auch schon 1946 direkt mit Arbeitskräfteanforderungen an die Umsiedlerbehörden wandten, erfolgte eine Festlegung des Aufnahmeortes entsprechend der beruflichen Eignung bzw. des Arbeitsplatzangebotes von seiten der Betriebe. Solche Vermittlungen konnten aber an mangelnden Unterbringungsmöglichkeiten oder der Verweigerung der Zuzugsgenehmigung durch lokale Behörden wieder scheitern. Seit dem Frühjahr 1947 häuften sich dann aber die Fälle, in denen Unternehmen eigenständig Arbeitskräfte in den "Umsiedler"-Quarantänelagern ${ }^{20}$ warben. So meldete die ZVU beispielsweise, daß in Sachsen-Anhalt Vertreter von Großbetrieben "mit Ausweisen des Landesarbeitsamtes“ eine direkte Anwerbung von Fachkräf-

$15 \mathrm{BAB}, \mathrm{DO} 2 / 58, \mathrm{Bl}$. 98, Schreiben der ZVAS vom 27. 11. 1945 an die ZVU.

16 Ebenda, Bl. 9, Notiz Chwalczyks vom 5. 12. 1945 betr. Zusammenarbeit mit der ZVAS.

17 Eine mit handschriftlichen Bemerkungen und Unterstreichungen versehene Fassung befindet sich in: $\mathrm{BAB}, \mathrm{DO} 2 / 58, \mathrm{Bl} .25 \mathrm{f}$. Die Anweisung war an alle Landes- und Provinzialämter für Arbeit und Sozialfürsorge sowie an die Landesämter für Umsiedler gerichtet.

18 BAB, DQ 2/2007, SMAD-Abt. Arbeitskraft am 12.12. 1946 an den Chef der 2. Abt. für Zivilangelegenheiten bei KDV-SMAD [sic] (Oberstleutnant Ugrjumow).

19 In der ursprünglichen Fassung war eine Registrierung nach Berufsgruppen vorgesehen. Diese Änderung ging auf eine Intervention der SMAD zurück. Vgl. BAB, DO 2/58, Bl. 32, Schreiben des Chefs der Abt. für Arbeitskraft bei der SMAD, Morenow, am 12. 12. 1946 an den Chef der 2. Abt. für Zivilangelegenheiten bei KDV-SMAD [sic], Oberstleutnant Ugrjumow.

20 Die Vertriebenen mußten sich in der Regel 14 Tage in den Quarantänelagern aufhalten, bevor sie in die Aufnahmeorte weitergeleitet wurden. Hintergrund dafür waren gesundheitspolitische Überlegungen der deutschen Verwaltungsstellen, die ein Ausbreiten von Seuchen schon im Keim erstikken wollten. Gleiches traf im übrigen auch die zurückkehrenden Kriegsgefangenen. Die SMAD schaltete sich bei der Seuchenbekämpfung sehr stark ein. Vgl. dazu BAB, DO 2/58, Bl. 207, Schreiben der ZVU an die Zentralverwaltung der Industrie vom 12. 9. 1947. 
ten in den Lagern vornehmen würden ${ }^{21}$. Nach Angaben Chwalczyks habe sich dieses System gut bewährt. Bereits am 9. September 1946 hatte das Präsidium der ZVU bei der SMAD den Vorschlag unterbreitet, den Großbetrieben mit einem anhaltend hohen Arbeitskräftebedarf eine besondere Genehmigung zur Werbung von Arbeitskräften in den Aufnahmelagern zu erteilen ${ }^{22}$. Dem standen offenkundig anderslautende Verfügungen der sowjetischen Besatzungsmacht entgegen. $\mathrm{Ob}$ diese daraufhin revidiert wurden, läßt sich nicht nachweisen. Festzuhalten bleibt aber, daß die Unternehmen an diesen Praktiken nicht gehindert wurden. Die Werbeaktionen einzelner Betriebe besaßen jedoch einen ambivalenten Charakter: Auf der einen Seite wurde dadurch die Arbeit der Arbeitsämter unterstützt, die den Arbeitskräftebedarf der Unternehmen offensichtlich nicht alleine bedienen konnten. Auf der anderen Seite zeigten sich damit aber die Schwächen staatlicher Interventionspolitik, die von einem politischen System, das den Anspruch besaß, den Arbeitsmarkt zentral regulieren $\mathrm{zu}$ wollen, nicht ohne weiteres hingenommen werden konnte.

In welchen Wirtschaftssektoren fanden nun die "Umsiedler“ vor allem eine Beschäftigung? Von insgesamt 1344588 in Arbeit stehenden Vertriebenen (Ende 1946) waren 588756 in der Land- und Forstwirtschaft beschäftigt. Das entsprach einem prozentualen Anteil von 43,823. An zweiter Stelle folgte der Bereich Industrie und Gewerbe mit 261337 „Umsiedlern“ (19,4 Prozent), gefolgt vom Bauund Baunebengewerbe mit 56237 (4,2 Prozent) und dem Bergbau sowie der Metallindustrie mit 33600 Vertriebenen (2,5 Prozent). Das Schlußlicht bildete die Gruppe der Selbständigen, zu denen 18887 (1,4 Prozent) gezählt wurden ${ }^{24}$. Diese Statistik verdeutlicht, daß in der Anfangszeit vor allem der primäre Sektor Arbeitsmöglichkeiten für die Neuankömmlinge anbieten konnte. Laut ZVU-Statistik waren am 1. Dezember 1946 84,1 Prozent der meldepflichtigen „Umsiedler“ in den Produktionsprozeß eingegliedert. Aufschlußreich waren aber vor allem die Zahlenangaben über die arbeitsfähigen Vertriebenen, machte sich doch hier eine enorme Kluft zur eingesessenen Bevölkerung bemerkbar: Nur 41,6 Prozent der „Umsiedler“ galten als arbeitsfähig25. Im Gegensatz dazu lag der vergleichbare Wert für die Gesamtbevölkerung um die Hälfte höher, nämlich bei 60,1 Prozent ${ }^{26}$. Die geringere Arbeitsfähigkeit der Vertriebenengruppe im Vergleich zur Gesamtbevölkerung bedeutete eine zusätzliche finanzielle Belastung für die Haushalte der Länder und Kommunen in Form von Fürsorgeunterstützungen ${ }^{27}$.

21 BAB, DO 2/58, Bl. 204, Aktennotiz Chwalczyks vom 31. 7. 1947. In dem Zusammenhang wurden die Leuna-Werke, die Buna-Werke und die Mitteldeutschen Braunkohlengruben namentlich genannt.

22 Ebenda, Bl. 27-29, hier Bl. 28, Schreiben des ZVU-Präsidenten, Rudolf Engel, vom 9.9. 1946 an den Chef der Abt. für Zivilangelegenheiten, Statistik und Verteilung der Umsiedler bei der KDVSMAD [sic]. Als Beispiele wurden die Leuna- und Buna-Werke, der Mansfelder Kupfer-Bergbau, allgemein der Kohlenbergbau, der Kali-Bergbau und die Textilindustrie angeführt.

23 Die folgenden Zahlen stammen aus einem Bericht der ZVU vom 18. 12. 1946. Erhebungszeitpunkt war der 1. 12. 1946. BAB, DO 2/58, Bl. 41.

24 Einschränkend muß jedoch hinzugefügt werden, daß 385771 „Umsiedler“ (28,7 Prozent) unter der Kategorie „Verschiedene“ zusammengefaßt wurden. Ebenda.

25 Ebenda, Bl. 38.

26 Zank, Wirtschaft und Arbeit, S. 33.

27 Vgl. zu diesem Zusammenhang Boldorf, Fürsorgeunterstützung in Deutschland. 
Es überrascht nicht, daß die berufliche Integration der Vertriebenen zunächst nur geringe Fortschritte machte. Dabei war die Arbeitsmarktlage 1945/46 zumindest für die männlichen „Umsiedler" noch vergleichsweise günstig: Noch im Oktober 1946 zählte man fast eine Million Männer im arbeitsfähigen Alter weniger als 1939. Nach Berechnungen von Wolfgang Zank hätte das Arbeitskräftedefizit ohne den Vertriebenenzustrom sogar noch höher, nämlich bei rund 1,8 Millionen gelegen ${ }^{28}$. Bemerkenswert war der 1946 allseits gemeldete Arbeitskräftebedarf, unter anderem auch an Hilfsarbeitern und Erntehelfern. Trotz dieser günstigen Ausgangslage waren Anfang 1946 beispielsweise in Sachsen-Anhalt nur 45 Prozent der Vertriebenen im arbeitsfähigen Alter mit einer Arbeitsstelle versorgt, darunter 13 Prozent berufsfremd. Als Vergleichsmaßstab sei die Beschäftigtenrate der erwerbsfähigen Männer in der DDR genannt, die im Oktober 1946 bei 69 Prozent lag. Zu diesem Zeitpunkt lag der Anteil der erwerbstätigen Vertriebenen bezogen auf die Bevölkerung im arbeitsfähigen Alter vermutlich erheblich unter 45 Prozent ${ }^{29}$. Sachsen-Anhalt nahm dabei sicherlich eine Sonderrolle ein, da das Land eine überdurchschnittliche Gewerbedichte und einen etwa im Vergleich zu Mecklenburg geringeren „Umsiedler“-Anteil aufwies.

Welche Konsequenzen ergaben sich nun aus diesen Rahmenbedingungen für die berufliche Eingliederung der Flüchtlinge und Vertriebene in den ostdeutschen Arbeitsmarkt? Zum einen mußten den Zuwanderern neue Beschäftigungsmöglichkeiten geboten werden; zum anderen waren die „Umsiedler" gezwungen, den Wohnort abermals zu wechseln und sich selbst einen Arbeitsplatz zu suchen. Was die Schaffung neuer Arbeitsplätze anbelangte, so nahm die im September 1945 eingeleitete Bodenreform ${ }^{30}$ einen wichtigen Stellenwert ein, den man aber nicht überbewerten sollte. In diesem Zusammenhang sollte nur kurz auf das Gesamtergebnis dieser staatlich verordneten und kontrollierten Neuverteilung von Land eingegangen werden, und zwar in Hinblick auf die Gruppe der „Umsiedler“31. Einer statistischen Erhebung vom Sommer 1948 zufolge hatten bis zu diesem Zeitpunkt 88000 Vertriebene Neubauernstellen erhalten; zusammen mit den Familienangehörigen kommt man auf eine Personengruppe von etwa 350000, die durch die Landwirtschaft versorgt werden konnte ${ }^{32}$. Nimmt man die Gesamtgruppe der Vertriebenen zum Maßstab (Ende 1946: 3,9 Millionen), so lag der Anteil unter zehn Prozent. Der Vertriebenenanteil unter den Neubauern lag in allen Ländern der SBZ - mit Ausnahme Mecklenburgs - leicht über dem jeweiligen Bevölkerungsanteil. Da die Mehrzahl der Vertriebenen jedoch erst zu einem späten Zeitpunkt in die SBZ gelangte, als sich die Bodenreform schon in einem weit fortgeschrittenen Stadium befand ${ }^{33}$, müssen die angedeuteten positiven Effekte stärker relativiert werden, zumal die weit überwiegende Mehrheit der im

28 Zank, Wirtschaft und Arbeit, S. 149.

29 Ebenda.

30 Ausführlich zu diesem Themenkomplex der Tagungsband von Bauerkämper, "Junkerland in Bauernhand"?

31 Vgl. dazu auch Bauerkämper, Die vorgetäuschte Integration.

32 Zank, Wirtschaft und Arbeit, S. 149. Ende 1946 lag die Zahl der Vertriebenen, die Neubauernstellen erhalten hatten, bei 77971. Vgl. Meinicke, Die Bodenreform und die Vertriebenen, S. 139.

$33 \mathrm{BAB}, \mathrm{DO} 2 / 4, \mathrm{Bl} .105$, Aussprache des Zentralsekretariats der SED mit 30 „Umsiedlern“, vermutlich im Frühjahr 1946. 
primären Sektor tätigen „Umsiedler“ vielmehr als Landarbeiter eine Beschäftigung fand ${ }^{34}$. Weniger von Bedeutung war dagegen die Tatsache, daß eine Reihe von Neubauern, die sich aus Sicht der SED „nicht bewährt hatten" 35 , durch andere Betriebsinhaber ersetzt werden mußte. Für die freiwerdenden Neubauernstellen boten sich - so das SED-Zentralsekretariat - die „antifaschistischen Bauern aus dem Sudetengebiet und aus Polen" 36 an. Diese Zahlen veränderten jedoch das Gesamtergebnis nur unwesentlich. Bei der Behauptung auf dem landwirtschaftlichen Arbeitsmarkt muß ein anderer Zusammenhang noch kurz beleuchtet werden: Für die Vertriebenen, die im Zuge der Bodenreform Land erhalten hatten, bedeutete die Benachteiligung bei der "Verteilung von lebendem und totem Inventar" eine enorme Verschlechterung ihrer Position im Konkurrenzkampf mit den alteingesessenen Bauern ${ }^{37}$. Das führte oftmals dazu, daß zahlreiche „Umsiedler" schon bald ihre neu erworbenen Höfe aufgeben mußten ${ }^{38}$.

Daneben erhielt für die Vertriebenen die Heimarbeit zunehmende Bedeutung und wurde staatlicherseits gefördert. Der erhoffte Effekt auf dem Arbeitsmarkt blieb jedoch aus bzw. stellte sich nicht in dem Maße ein, wie es die Arbeitsverwaltung erwartet hatte. Die staatlich unterstützte Gründung von Produktionsgenossenschaften beschränkte sich bei den "Umsiedlern" oftmals auf Betriebe, die kunstgewerbliche Produkte herstellten, wie etwa das Beispiel des Gablonzer Kunsthandwerks in Thüringen anschaulich zeigt ${ }^{39}$. Bei der Totalbetrachtung des Arbeitsmarktes in der SBZ und frühen DDR muß die Bedeutung der Produktionsgenossenschaften stark relativiert werden: So arbeiteten 1948 etwa 8000 Vertriebene in 61 Genossenschaften, also 0,6 Prozent der erwerbstätigen „Umsiedler" ${ }^{40}$. Schwierigkeiten ergaben sich für Vertriebene beim Aufbau eigener Handwerksbetriebe. Dies hing mit der unzureichenden Ausstattung mit Werkzeugen, aber auch mit dem Monopolanspruch eingesessener Handwerksmeister zusammen, die neue Konkurrenz befürchteten. So wurde auf einer „Umsiedler“-Konferenz der SED-Führung am 14. Juni 1946 in Berlin allgemein beklagt, daß die Handwerkskammern "Widerstand bei der Selbständigmachung von Umsiedlern“ leisten würden ${ }^{41}$. Die „Niederlassung von selbständigen Umsiedlern“ sei in einigen Orten mit dem Hinweis unterbunden worden, daß ansonsten die "noch in Kriegsgefangenschaft befindlichen Handwerksmeister bei ihrer Rückkehr keine Betätigungsmöglichkeit" mehr hätten ${ }^{42}$. Der starke Zustrom von Vertriebenen bedeute jedoch einen "Mehrbedarf" an Arbeitsplätzen im handwerklichen Bereich. Die SED-Führung konnte in dem Zusammenhang nur an die Arbeitsämter appellieren, bei der Vergabe von Arbeitsplätzen „Umsiedler“ bevorzugt zu berücksichtigen. Die eigentlichen Beharrungskräfte gegen eine gleichberechtigte Eingliede-

34 So auch dic Schlußfolgerung bei Bauerkämper, Von der Bodenreform zur Kollektivierung, S. 126.

$35 \mathrm{BAB}, \mathrm{DO} 2 / 4, \mathrm{Bl}$. 105, Aussprache des Zentralsekretariats der SED mit 30 „Umsiedlern“, vermulich im Frühjahr 1946.

36 Ebenda.

37 Meinicke, Die Bodenreform und die Vertricbenen, S. 140.

38 Vgl. Schwartz, Vom Flüchtling zum Neubürger, S. 34.

39 Vgl. Kaltenborn, Der Versuch zur Wiederbelebung des Gablonzer Kunsthandwerks.

40 Zank, Wirtschaft und Arbeit, S. 150.

$41 \mathrm{BAB}, \mathrm{DO} 2 / 4, \mathrm{Bl}$. 99, Konferenz von Vertretern der „Umsiedler“ aus den Ländern und Provinzen der SBZ am 14.6. 1946 in Berlin.

+2 Ebenda, Bl. 100. 
rung der Vertriebenen befanden sich aber auf der lokalen Ebene. Dort konnte der staatlichen Interventionspolitik zum Teil erfolgreich entgegengesteuert werden.

$\mathrm{Da}$ die Bemühungen zur Schaffung neuer Arbeitsplätze am Aufenthaltsort der Vertriebenen insgesamt nur begrenzten Erfolg hatten, waren zahlreiche Vertriebene gezwungen, ihren Wohnort aufzugeben. Ein zweiter Ortswechsel und eine Binnenwanderung waren die Folge. Daneben hatte schon Anfang 1946 eine Weiterwanderung gen Westen eingesetzt. Vor allem die amerikanische Militärregierung empfand diese Zuwanderung als Belastung für die eigene Zone und ging bald dazu über, die Reisen aus der SBZ in die Westzonen - soweit das überhaupt möglich war - zu regulieren und einzuschränken. Ganz anders verhielt sich die britische Besatzungsmacht, die offensichtlich bereit war, alle Neuankömmlinge in ihrer Zone aufzunehmen ${ }^{43}$. Um die massenhafte Abwanderung in den Westen zu stoppen, erließ der Alliierte Kontrollrat auf Antrag der sowjetischen Seite am 30. Juni 1946 eine Grenzsperre für Flüchtlinge aus der SBZ44. Eine genaue Quantifizierung dieses Zustroms ist aufgrund der zu diesem frühen Zeitpunkt noch unvollständigen statistischen Erhebungen kaum möglich; es muß jedoch für die Phase bis zur Staatsgründung der DDR 1949 wahrscheinlich von einigen Tausend ausgegangen werden ${ }^{45}$.

Zielpunkte der Binnenmigration ${ }^{46}$ waren vor allem Großbetriebe oder Großprojekte wie beispielsweise der Uranbergbau im Erzgebirge ${ }^{47}$. Nach Ansicht der ZVU war der Arbeitskräftebedarf weitaus größer, als daß er allein von der Gruppe der „Umsiedler“ hätte befriedigt werden können ${ }^{48}$. Gleichzeitig wurde aber auch beklagt, daß die Vertriebenen von den Arbeitsämtern oftmals nur als Manövriermasse betrachtet würden. So hätte die Arbeitsverwaltung bei der Durchführung von SMAD-Befehlen zur Zusammenstellung von Arbeitskräftekontingenten „besonders gerne Umsiedler herangezogen "49. Als Beispiele führte der ZVU-Präsident den Oder-Deichbau und den Bergbau an. Die Notwendigkeit dieser Arbeiten müsse, so Rudolf Engel weiter, „besser popularisiert werden“. Darüber hinaus seien auch die Methoden der Arbeitsverpflichtung zu verbessern. Konkret nannte Engel die katastrophale Lage auf dem Wohnungsmarkt und die Benachteiligung der "Umsiedler" bei der Vergabe von Wohnraum. In den ersten beiden Nachkriegsjahren war die Versorgung mit Wohnraum und Lebensmitteln etwa für die Bergarbeiter der Wismut AG allgemein schlecht; dies belegen die zahlreichen Berichte der örtlichen Verwaltungen. 1947/48 änderte sich jedoch allmählich die

43 Die britische Zone war bei der Aufnahme der Deutschen aus der SBZ bis 1949 führend. Vgl. Heidemeyer, Flucht und Zuwanderung, S. 74 und 83 f. Eine konträre Position bezieht Zank, der davon ausgeht, daß die britische Militärregierung am 30. 6. 1946 einc vollständige Grenzsperre verhängte. Vgl. Zank, Wirtschaft und Arbeit, S. 150.

t+ Heidemeyer, Flucht und Zuwanderung, S. 75.

45 Nach Angaben Meinickes waren von den mindestens 2,7 Millionen Menschen, die bis zum Mauerbau die DDR verließen, etwa 950000 Vertriebene. Meinicke, Flüchtlinge, S. 79. Vgl. zur Flüchtlingspolitik der Bundesregierung allgemein die detaillierte Studie von Heidemeyer, Flucht und Zuwanderung.

46 Vgl. Ther, Deutsche und polnische Vertriebene, S. 269-271.

47 Vgl. allgemein zu Vertriebenen im Uranbergbau: Jahn, Zur sächsischen Spezifik der Aufnahme.

t8 BAB, DO 2/4, Bl. 50, Erfahrungsbericht des Präsidenten der ZVU, Rudolf Engel, o.D. (vermutlich Ende 1947)

+9 Ebenda. 
soziale Lage der Beschäftigten im Uranbergbau. In zunehmenden Maße wurden Sonderrationen ausgegeben, und bei der Wohnungsvergabe genossen die WismutArbeiter bald Priorität. Diese Entwicklung hing aufs engste mit dem Wechsel der Instrumentarien staatlicher Arbeitskräftelenkung zusammen. Während - vereinfacht gesehen - zuvor die Zwangseinweisung auf der Tagesordnung stand, bemühten sich die Arbeitsbehörden nunmehr, Arbeitskräfte auf freiwilliger Basis zu werben. Dies kam den „Umsiedlern“ durchaus entgegen, waren sie doch bei der Vergabe von Wohnraum oft gegenüber der einheimischen Bevölkerung benachteiligt worden. Der Wechsel in der Rekrutierungspolitik gerade für den Uranbergbau, also fort von "harten“ und hin zu "weichen“ Maßnahmen, wurde auch dadurch erheblich begünstigt, daß in Gestalt der Vertriebenen ein noch ungebundenes und dringend auf Arbeit und Unterkunft angewiesenes Arbeitskräftereservoir zur Verfügung stand. Im Ergebnis wiesen bereits 1948 die Belegschaften einzelner Großbetriebe einen weit überdurchschnittlichen Anteil an Vertriebenen auf. Für die fünfziger Jahre stellt mit Sicherheit das Eisenhüttenkombinat Ost in Fürstenwalde ein Paradebeispiel für die Eingliederung einer quantitativ nicht unbeträchtlichen Gruppe von "Umsiedlern“ in den Arbeitsmarkt dar. Umfragen zufolge lag der Vertriebenenanteil 1952 in 34 Großbetrieben bei 39 Prozent $^{50}$. An der Spitze befanden sich die Leuna-Werke mit 11800 „Umsiedlern“, was einem Belegschaftsanteil von 47 Prozent entsprach. Auch die Gruben der Wismut AG in Sachsen und Thüringen wiesen einen hohen Anteil auf, in einzelnen Fällen soll der Vertriebenenanteil sogar 80 Prozent betragen haben ${ }^{51}$.

Trotz dieser Erfolge erhöhte sich vom Oktober 1946 bis zum März 1949 die Gesamtzahl der erwerbstätigen Vertriebenen kaum: Zu beiden Zeitpunkten lag sie bei etwa 1,4 Millionen ${ }^{52}$. Der Beschäftigungsanstieg durch Binnenwanderung und Schaffung von Arbeitsmöglichkeiten auf dem Land wurde durch den raschen Anstieg der Arbeitslosigkeit und die zunehmende Konkurrenz mit den Kriegsheimkehrern und die auf den Arbeitsmarkt gedrängten arbeitseinsatzfähigen Frauen wieder zunichte gemacht. Da im selben Zeitraum die Zahl der „Umsiedler" noch einmal um 700000 bis 800000 anstieg, sank somit der Anteil der Erwerbstätigen an der Vertriebenengruppe. Diese Entwicklung kann nur zu einem kleinen Teil durch den andersartigen demographischen Aufbau der Vertriebenengruppe erklärt werden, d.h. durch den höheren Anteil an Alten, Invaliden und Kranken, die nicht mehr in den Arbeitsmarkt eingebunden werden konnten. Es muß insgesamt festgestellt werden, daß die "Umsiedler" auf dem Arbeitsmarkt auch noch 1949 erheblich benachteiligt waren. $\mathrm{Da}$ angesichts der Eigentumsverluste und der eher bescheidenen staatlichen Unterstützung, die zunächst nur eine Ad-hoc-Maßnahme darstellte und die erste Not lindern konnte, das Überleben von einer Erwerbstätigkeit abhing, waren die Vertriebenen in doppelter Hinsicht benachteiligt. Die Lösung der Integrationsaufgabe stand somit bei der Gründung der DDR im Oktober 1949 noch aus.

so Zank, Wirtschaft und Arbeit, S. 151. Zank stützt sich dabei auf Untersuchungsergebnisse von Seraphim. Vgl. Seraphim, Die Heimatvertriebenen, S. 96.

51 Seraphim, Die Heimatvertriebenen, S. 97. Der Autor zitiert an dieser Stelle Informationsberichte, ohne deren Herkunft anzugeben.

52 Zu dicsem Urteil kommt Zank. Vgl. Zank, Wirtschaft und Arbeit, S. 151. 
Erste Voraussetzung für eine erfolgreiche Arbeitsplatzvermittlung blieb, wie schon erwähnt, die Registrierung der arbeitsfähigen Bevölkerung durch die Arbeitsämter. In den Monats- und Quartalsberichten, die auf Landes- und auf Zentralebene gebündelt wurden, tauchen die „Umsiedler“ nur bis Anfang 1949 als Kategorie auf. Für die Arbeitsverwaltung existierten noch eine ganze Reihe anderer sozialer Gruppen, deren berufliche Integration problematisch erschien. Dies waren vor allem die Frauen und die Schwerbeschädigten ${ }^{53}$. Die statistische Erfassung der arbeitsfähigen, erwerbstätigen und arbeitslosen „Umsiedler“ bricht Ende Mai 1949 aufgrund eines Erlasses der zuständigen Hauptverwaltung für Arbeit und Sozialfürsorge (HVAS) ab54. Inwieweit die SED-Führung hinter diesem Beschluß stand, kann aus der Retrospektive nicht mehr ermittelt werden. $\mathrm{Zu}$ vermuten wäre aber, daß dieser Schritt als verspätete Konsequenz der Auflösung der Flüchtlingssonderverwaltung ZVU und ihrer Eingliederung in die Innenverwaltung erfolgte 55 .

Aufnahme und Eingliederung von Flüchtlingen und Vertriebenen war in der Anfangszeit zunächst eine Aufgabe der Landes- und Provinzialverwaltungen. Sie konnten sich in dieser frühen Phase (1945/46) den besten Überblick über den genauen Zustrom der „Umsiedler" verschaffen, während die im Spätsommer 1945 aufgebauten Zentralverwaltungen noch keine Vorstellungen über die damit zusammenhängenden Probleme besaßen. Die für die Registrierung der „Umsiedler“ zuständige ZVAS versuchte allerdings rasch, die Aktivitäten der Länder bzw. Provinzen zu koordinieren. Dabei wurde der berufsmäßigen Registrierung der Vertriebenen große Bedeutung beigemessen, da dies eine zentrale Voraussetzung für die Lenkung des Flüchtlingsstroms war. Anfang Oktober 1945 lagen nur für die Länder Brandenburg, Mecklenburg sowie für die Provinz Sachsen erste Zahlenangaben vor ${ }^{56}$. Eine restlose Zählung der Flüchtlinge konnte nach Angaben der ZVAS erst Ende 1945 beginnen: Es sei anzunehmen, daß „mit Anbrechung der kalten Jahreszeit und Abebben des Zustroms neuer Flüchtlinge, [...] die Flüchtlinge nunmehr im allgemeinen eine feste Unterkunft gefunden haben" 57 .

Aufgrund von ersten Statistiken einzelner lokaler Behörden glaubte die ZVAS einen ersten, vorläufigen Plan zur beruflichen Eingliederung der Vertriebenen ausarbeiten zu können. Sie ging davon aus, daß „der größte Teil der männlichen Bevölkerung [gemeint ist die Gruppe der Flüchtlinge] aus Altersgründen nicht voll arbeitsfähig, aber in der Landwirtschaft als Landarbeiter oder in männerlosen

53 Vgl. Boldorf, Eingliederung der Kriegsopfer und Schwerbeschädigten.

54 Dies geht aus einem Schreiben des Ministers für Arbeit und Sozialpolitik der Landesregierung Sachsen-Anhalt vom 14. 7. 1949 an die HVAS hervor, in: BAB, DQ 2/1082. Die letzte statistische Erhebung der „Umsiedler" erfolgte in einigen Ländern bereits Ende März 1949. Vgl. BAB, DQ 2/ 1968, Situationsbericht des mecklenburgischen Ministeriums für Sozialwesen für Juni '49 sowic das II. Quartal und 1. Halbjahr '49, S. 12.

55 Vgl. zum Auflösungsprozeß der ZVU Schwartz, Zwischen Zusammenbruch und Stalinisierung, S. 57-59.

56 BAB, DO 2/58, Bl. 90-94, Bericht der Abt. II (Erfassung und Arbeitseinsatz der Bevölkerung) der ZVAS vom 5. 10. 1945. Die Zahlen lauteten für Brandenburg (700000), Provinz Sachsen (2 Millionen) und Mecklenburg (1 Millionen). Die ZVAS ging zu diesem Zeitpunkt davon aus, daß insgesamt 12 Millionen Flüchtlinge [sic] in der SBZ "untergebracht werden müssen“. Vgl. ebenda, Bl. 90.

5) Ebenda. 
Bauernwirtschaften oder als Siedler untergebracht werden kann"58. Für die landwirtschaftlichen Berufe sei „erfahrungsgemäß [...], Voll-Arbeitsfähigkeit" im städtischen Sinne nicht Voraussetzung der Einsatzfähigkeit“. Im primären Sektor müßten daher - so die Schlußfolgerung der Zentralverwaltung - zusätzliche Arbeitsplätze geschaffen werden. Dies könne aber mit Aussicht auf Erfolg nur durch "Zwangsauflage von Arbeitskräften, verteilt auf die einzelnen Betriebe“ erfolgen. Eine solche Maßnahme, die Widerspruch hervorrufen werde, diene unter anderem auch der Intensivierung der landwirtschaftlichen Erzeugung. Die Eingliederung der Jugendlichen in den Arbeitsprozeß schätzte die ZVAS nur als „vorübergehend[es]" Problem ein. Die Jugend stellte nach den Vorstellungen der ZVAS die wichtigste Arbeitskraftreserve für die Mangelberufe dar. Dagegen wurde die berufliche Eingliederung von Frauen als äußerst problematisch angesehen, da bereits bei der einheimischen weiblichen Bevölkerung eine hohe Arbeitslosigkeit herrsche $^{59}$. Der von der ZVAS ausgearbeitete Plan zeigte, daß die Zentralverwaltung zu diesem Zeitpunkt noch keine genauen Zahlenangaben über die Verteilung der „Umsiedler“ in den einzelnen Ländern bzw. Provinzen besaß und daher nur allgemeine Aussagen machen konnte. Darüber hinaus fällt die besondere Hervorhebung der Landwirtschaft auf. Angesichts der Demontagen industrieller Anlagen, die gleich nach Kriegsende begannen, und der ungelösten Transportprobleme schien für die Zentralverwaltung der primäre Wirtschaftssektor die besten Möglichkeiten zur beruflichen Eingliederung von „Umsiedlern“ zu bieten.

Die unterschiedlichen Arbeitsmarktbedingungen in den Ländern und Provinzen der SBZ machten aus Sicht der Arbeitsverwaltung eine koordinierte Binnenwanderung der „Umsiedler" erforderlich. Dadurch erhoffte man sich eine rasche berufliche Eingliederung der Zugewanderten entsprechend ihrer Qualifikation. Eine berufsmäßige Erfassung der arbeitsfähigen „Umsiedler“ in 2716 Gemeinden Sachsen-Anhalts hatte ergeben, daß 33 Prozent in ihren erlernten Berufen wieder eingesetzt werden konnten ${ }^{60}$. Ein weiteres Drittel war arbeitslos gemeldet und etwa zwölf Prozent der Vertriebenen mußte in einem fremden Beruf arbeiten ${ }^{61}$. Aus Sicht des Vizepräsidenten der ZVU, Michael Tschesnow, waren diese Zahlenangaben aber nur bedingt aussagekräftig. So würden viele „Umsiedler“ ihren erlernten Beruf oftmals nicht angeben, um ihre neue Arbeitsstelle nicht wechseln zu müssen.

ZVAS und ZVU erblickten in der auf die Erfordernisse des Arbeitsmarktes zugeschnittenen „Lenkung" von Flüchtlingen innerhalb der SBZ eine Möglichkeit, den unkontrollierten Zustrom, der bis zum Jahreswechsel 1945/46 angehalten hatte, nachträglich doch noch zu korrigieren. Da sich aber auch schon lokale Verwaltungen anschickten, Vertriebene in andere Gebiete abzuschieben ${ }^{62}$, wollten die beiden Zentralverwaltungen darüber hinaus erreichen, daß der Personentransfer

58 Ebenda, Bl. 92.

59 Ebenda, Bl. 93.

$60 \mathrm{BAB}, \mathrm{DO} 2 / 4, \mathrm{Bl} .88$, Denkschrift Tschesnows, o.D. (vermutlich vom Sommer 1946).

"1 Der Rest entfiel mit 15 Prozent auf die Kategorie „Hausfrau“ sowie sieben Prozent „Einsatzunfähige“. Vgl. ebenda. Ähnliche Zahlenangaben finden sich auch bei Zank, Wirtschaft und Arbeit, S. 149.

62 Zu den Motiven der lokalen Verwaltungsstellen zählten neben der jeweiligen Arbeitsmarktlage auch die z.T. katastrophale Lage auf dem Wohnungsmarkt. 
zwischen den Ländern und Provinzen koordiniert, d.h. unter der Regie der jeweiligen Arbeits- und Umsiedlerämter ablief. Vor allem die ZVAS drängte darauf, daß „bei der Lenkung von Umsiedlern aus einer in die andere Provinz vorher die $\mathrm{Zu}$ stimmung der betreffenden Landesarbeitsämter eingeholt" werden müsse ${ }^{63}$. Es sei „unmöglich, daß einzelne Firmen qualifizierte Arbeiter aus Umsiedlerkreisen, die sich in einer anderen Provinz befinden, ohne die Genehmigung des überbezirklichen Austausches einstellen" ${ }^{64}$. ZVAS und ZVU trafen sogar eine Abmachung, wonach Transporte nur nach vorheriger Vereinbarung mit den Landesarbeitsämtern und den Umsiedlerabteilungen des abgebenden und des aufnehmenden Landes zu genehmigen waren ${ }^{65}$. Obwohl diese Abmachung von der SMAD in Karlshorst gebilligt worden war, setzten sich einzelne sowjetische Dienststellen auf der Landesebene darüber hinweg. So war auf Befehl der SMA Mecklenburg am 8. November 1946 ein Transport von Textilarbeitern nach Sachsen abgeschickt worden, der dort von der Landesverwaltung nicht betreut werden konnte, weil weder die Landesarbeitsämter noch die Umsiedlerämter in diese Aktion eingeweiht waren. Daraufhin wurde die ZVU bei der SMAD in Karlshorst vorstellig und bat, "die SMA in den Ländern und Provinzen auf diese Vereinbarungen hinzuweisen" 66 .

Die organisatorischen Schwierigkeiten bei der Übersiedlung von arbeitsfähigen Vertriebenen in andere Länder sollen im folgenden am Beispiel der Textil-, Glasund Bergarbeiter in Mecklenburg veranschaulicht werden. Die Konflikte zwischen den beiden Zentralverwaltungen ZVAS und ZVU auf der einen Seite und den Landesverwaltungen auf der anderen Seite treten dabei deutlich hervor. Vertreter der DVAS, der ZVU und des FDGB hatten bei einer Besprechung gemeinsam festgestellt, daß sich im nördlichsten Land der SBZ zahlreiche Textil-, Glasund Bergarbeiter aufhielten, die dort nicht benötigt wurden ${ }^{67}$ und statt dessen in Sachsen angesiedelt werden sollten ${ }^{68}$. Aufgrund des bei Kriegsende zusammengebrochenen Verkehrsnetzes und der vordringlichen Bereitstellung von Eisenbahnzügen für die sowjetische Besatzungsmacht mußte der Personentransport aus Mecklenburg nach Sachsen mehrmals verschoben werden ${ }^{69}$. Erst Anfang Mai 1947 konnte mit den ersten Transporten begonnen werden ${ }^{70}$.

63 Dies geht aus einer Aktennotiz der Organisationsabteilung der ZVU vom 6. 9. 1946 hervor, in: BAB, DO 2/58, Bl. 115.

64 Ebenda.

65 Vgl. BAB, DO 2/58, Bl. 118, Aktennotiz der Organisationsabteilung der ZVU vom 24. 9. 1946. Der ZVU-Präsident teilte der SMAD den Inhalt dieser Vereinbarung einige Wochen später mit. Vgl. ebenda, Bl. 30, Schreiben vom 12.11. 1946 an den Chef der Abteilung für Zivilangelegenheiten, Statistik und Verteilung der deutschen Umsiedler bei der KDV-SMAD [sic].

66 Ebenda, Bl. 31, Schreiben des Vizepräsidenten der ZVU, Michael Tschesnow, vom 28. 11. 1946 an den Chef der Abteilung für Zivilangelegenheiten, Statistik und Verteilung der deutschen Umsiedler bei der KDV-SMAD.

67 $\mathrm{BAB}, \mathrm{DO} 2 / 30, \mathrm{Bl} .198$, Bericht über die Besprechung bei der DVAS am 27. 11. 1946.

68 Ebenda, Bl. 199, Aktennotiz Riedels (Abt. Organisation), o.D. (handschriftlich: 15. 12. 1946).

69 So hatte die SMA in Mecklenburg noch im November angeordnet, daß bis zum 1.12. 1946 kein „Transportraum“ zur Verfügung gestellt werden dürfe. Vgl. BAB, DO 2/58, Bl. 144, Aktennotiz Riedels (ZVU) vom 28. 11. 1946.

$70 \mathrm{BAB}, \mathrm{DO}$ 2/58, Bl. 185, Schreiben des Landesarbeitsamtes Sachsen vom 22.5. 1947 an die ZVU. Eine Gesamtzahl der umzusiedelnden Vertriebenen taucht nicht auf. Es muß sich jedoch um einige Tausend gehandelt haben. So weigerte sich etwa im März 1947 das Amt für Neubürger in Weimar 20000 Textilfacharbeiter aus Mecklenburg aufzunehmen. Zwischenzeitlich war auch Thüringen 
Die sächsische Landesverwaltung hatte frühzeitig versucht, die Zahl der aufzunehmenden "Umsiedler" mit dem Aufnahmekontingent, welches Sachsen zu erfüllen hatte, verrechnen zu lassen. Die Umsiedlungsaktion sollte mit anderen Worten dazu genutzt werden, den sächsischen Arbeitsmarkt zu bereinigen: Textilfacharbeiter, die man selber brauchte, sollten aufgenommen werden und im Gegenzug arbeitslose Vertriebene, für die kein Arbeitsplatz bereitgestellt werden konnte, abgeschoben werden. Die ZVU hatte sich ganz entschieden gegen diesen Vorschlag ausgesprochen ${ }^{71}$. In der Praxis schien sich jedoch zunächst der vom sächsischen Landesarbeitsamt favorisierte Weg durchzusetzen: Mecklenburgs Landesverwaltung erklärte sich bereit, im Gegenzug eine entsprechende Anzahl von Vertriebenen aus Sachsen aufzunehmen. Das Zentralsekretariat der SED stoppte diesen Handel im Spätsommer 1947 und erklärte, es könne nicht angehen, daß Sachsen die so dringend benötigten Facharbeiter auf das Aufnahmesoll an "Umsiedlern“" angerechnet bekomme ${ }^{72}$.

Als weiterer Konfliktpunkt erwies sich die Frage, aus welchen Haushaltsmitteln die anfallenden Transportkosten zu begleichen waren. Obwohl sich die beteiligten Landesverwaltungen mit der ZVU darauf geeinigt hatten, daß das jeweils „abgebende Land“ die Transportkosten übernehmen sollte, fühlte sich das Landesarbeitsamt Schwerin an diese Vereinbarung nicht mehr gebunden ${ }^{73}$. Auch in dieser Frage scheinen sich DVAS und ZVU gegenüber den Landesverwaltungen durchgesetzt zu haben. Sehr viel größeren Erfolg hatten jedoch die Länder bei ihrer Auseinandersetzung mit den beiden Berliner Zentralverwaltungen, wenn sie auf die eigene angespannte Arbeitsmarktsituation verwiesen. Auf diesem Wege gelang es beispielsweise Thüringen, die Übernahme von 20000 Textilfacharbeitern $^{74}$ aus Mecklenburg abzuwenden. So erklärte das Amt für Arbeit und Sozialfürsorge in Weimar, daß die Textilindustrie in Thüringen aufgrund von Rohstoffmangel „nur noch in halber Schicht“ arbeiten würde ${ }^{75}$. Damit gelang es der thüringischen Arbeitsverwaltung zunächst einmal, den Zeitpunkt der Umsiedlungsaktion hinauszuschieben. Ob die Übernahme der Textilfacharbeiter aus Mecklenburg in Thüringen überhaupt verwirklicht wurde, kann nicht mehr geklärt werden.

Bei der Arbeitsmarktintegration der Vertriebenen mußten sich zwangsläufig Kompetenzkonflikte auch zwischen den beteiligten Zentralverwaltungen, der ZVAS und der ZVU, ergeben, die aus dem Konkurrenzverhältnis zweier kooperierender Behörden herrührten. Die Zusammenarbeit mußte erst eingeübt werden und verlief keineswegs konfliktfrei. So beklagte etwa der DVAS-Präsident Gustav Brack am 11. Oktober 1946, daß die ZVU noch nicht ihre Zustimmung gegeben

als Bestimmungsland für die „Umsiedler" vorgesehen. Vgl. ebenda, Bl. 166, Schreiben der DVAS vom 4. 3. 1947 an die ZVU.

7 SächsHStA, Landesregierung Sachsen, Ministerium für Arbeit und Sozialfürsorge, Bd. 416, Schreiben Chwalczyks vom 20. 8.1946 an das Landesarbeitsamt Sachsen.

$72 \mathrm{BAB}, \mathrm{DO} 2 / 58, \mathrm{Bl} .208$, Schreiben der Abt. Arbeit und Sozialfürsorge beim Zentralsekretariat der SED vom 5. 9. 1947 an den Vizepräsidenten der ZVU Philipp Daub.

73 Ebenda, Bl. 185, Schreiben des sächsischen Landesarbeitsamtes vom 22. 5. 1947 an die ZVU.

74 Nach Angaben der ZVU handelte es sich hierbei um 20000 "Umsiedler“, d. h. einschließlich der Familienangehörigen. Vgl. BAB, DO 2/58, Bl. 169, Schreiben der ZVU vom 14.3. 1947 an die DVAS.

75 Zitiert nach Schreiben der DVAS vom 4. 3. 1947 an die ZVU, in: ebenda, Bl. 166. 
habe für die „Umsetzung" von Textil- und Bergarbeitern aus Mecklenburg, die in Halle, aber auch in Sachsen und Thüringen dringend benötigt würden. Es wäre „betrüblich“, wenn diese Aktion am hinhaltenden Widerstand der ZVU scheitern würde ${ }^{76}$. Er unterstrich, daß die Vermittlung von Arbeitskräften ausschließlich der DVAS übertragen worden sei. Die ZVU verwies ihrerseits darauf, daß die Zustimmung für eine Überführung der Arbeitskräfte nur dann gegeben werden könne, wenn die „wohnungsmäßige Unterbringung" gesichert sei”7. Auf Veranlassung der SMAD wurden die Zuständigkeitsbereiche der ZVU im Frühjahr 1947 eng zugeschnitten: Bei Fragen der Arbeitskräftelenkung sowie allgemein der Arbeitsmarktpolitik sollte die Tätigkeit der „Umsiedler“-Verwaltung „informatorischer und beratender Natur" sein $^{78}$. Der Konflikt hatte deutlich gemacht, daß die Arbeitsvermittlung allein zum Tätigkeitsbereich der DVAS gehörte, was die ZVU letztlich auch anerkennen mußte. Ihr verblieb nur die Möglichkeit, unter Hinweis auf die schlechte Wohnraumversorgung einzelne „Umsiedler“-Transporte zeitlich hinauszuzögern.

Auffallend ist, daß die ZVU besonders die Tätigkeit der Arbeitsämter wiederholt kritisierte, denen sie mangelnde Rücksichtnahme gegenüber den Flüchtlingen und Vertriebenen vorwarf. So wurde der Arbeitsverwaltung etwa auf einer „Umsiedler"-Konferenz am 14. Juni 1946 vorgehalten, daß sie bei der beruflichen Eingliederung versagen würde ${ }^{79}$. An dieser Kontroverse zeigte sich aber auch, daß die berufliche Integration der Vertriebenen aufs engste mit anderen Problembereichen verknüpft war, besonders mit der unzureichenden und mangelhaften Wohnraumversorgung ${ }^{80}$. Oftmals legten nämlich die freien Wohnraumkapazitäten die weitere Verteilung bzw. Lenkung der "Umsiedler" fest; dagegen gerieten arbeitsmarktpolitische Gesichtspunkte in den Hintergrund. Fehlende Unterbringungsmöglichkeiten waren zwar ein gesamtdeutsches Phänomen in der unmittelbaren Nachkriegszeit, das einen Großteil der Bevölkerung essentiell tangierte. Bei der Allokation dieses knappen Gutes hatten die Flüchtlinge und Vertriebenen jedoch häufig das Nachsehen gegenüber der eingesessenen Bevölkerung. So kam es zu der paradoxen Situation, daß die Neuankömmlinge auf der einen Seite einen vergleichsweise hohen Mobilitätsgrad aufwiesen, auf der anderen Seite eine sinnvolle Lenkung aufgrund der Bedürfnisse des Arbeitsmarktes durch einen Mangel an Wohnraum wieder zunichte gemacht werden konnte. So wies die DVAS-Abteilung II darauf hin, daß bei der Arbeitsplatzzuteilung für "Umsiedler“ generell Schwierigkeiten aufgetreten seien, „als an einigen Stellen Arbeitsplätze frei sind, jedoch infolge Überbelegung der Quartiere keine Möglichkeit zur Unterkunftsbeschaffung vorhanden ist" ${ }^{\text {"81. }}$. Als Beispiele wurden die Anhaltischen Kohlen-

76 Ebenda, Bl. 120, Schreiben Bracks vom 11.10.1946 an den ZVU-Präsidenten.

77 Ebenda, Bl. 128, Schreiben des ZVU-Präsidiums vom 2.11. 1946 an den DVAS-Präsidenten Brack.

$78 \mathrm{BAB}, \mathrm{DQ}$ 2/1711, Protokoll der DVAS (Abt. I b) über die Zusammenkunft mit der ZVU am 2.6. 1947.

$79 \mathrm{BAB}, \mathrm{DO} 2 / 4, \mathrm{Bl} .98-101$, hier Bl. 99, Bericht über die Konferenz von Vertretern der „Umsiedler“ aus den Ländern und Provinzen der SBZ am 14. 6. 1946 in Berlin.

80 Vgl. für Thüringen Kaltenborn, Wohn- und Lebensverhältnisse von Vertriebenen; die enge Verbindung von Arbeitsmarkt- und Wohnungspolitik betont auch Schwartz, Vertrieben in die Arbeiterschaft.

81 BAB, DQ 2/2007, Aktenvermerk der DVAS-Abt. II vom 8. 10. 1946. 
werke AG in Senftenberg sowie die Firma Zeiss in Jena genannt. Die ZVU stellte sich auf den Standpunkt, daß erst nach Zuweisung eines Arbeitsplatzes die Beschaffung von Wohnraum sinnvoll sei. Genau umgekehrt argumentierte die ZVAS sowie die ihr unterstellten Arbeitsämter. Die Wohnungsämter ihrerseits verlangten den Nachweis eines Arbeitsplatzes als Voraussetzung für die Zuteilung von Wohnraum. Auf diese Art und Weise wurden die „Umsiedler" letztlich von einer Institution zur anderen weitergereicht. Die Auseinandersetzung zwischen Arbeits- und „Umsiedler"-Verwaltung zog sich trotz Klärung der jeweiligen $\mathrm{Zu}$ ständigkeitsbereiche noch bis 1948 hin. In einer Denkschrift, die kurz nach Auflösung der ZVU und vor der Neuorganisation innerhalb der Deutschen Verwaltung des Innern (DVdI) im Frühjahr/Sommer 1948 entstand, verlangte der frühere Abteilungsleiter Chwalczyk eine Verbesserung der Tätigkeit der Arbeitsämter. In der ihm eigenen Behördensprache versuchte er nochmals deutlich zu machen, daß die Arbeitsverwaltung die „endgültige Wiederseßhaftmachung“ der „Umsiedler" zu fördern habe82. Es müsse alles getan werden, um den Vertriebenen das Gefühl zu vermitteln, „einen Dauerwohnplatz mit gesicherter Existenz gefunden zu haben" 83 .

Aus Sicht der ZVAS blieb jedoch die Vermittlung eines Arbeitsplatzes mit der Wohnraumfrage gekoppelt, die im Untersuchungszeitraum nie befriedigend gelöst werden konnte. Darüber hinaus stellten die „Umsiedler" für die Arbeitsverwaltung nur eine Personengruppe von vielen anderen dar, die in den Arbeitsmarkt einzubinden waren. Die Juristische Abteilung der DVAS vertrat den Standpunkt, daß „die Frage Ostumsiedler oder nicht für jede Arbeitsverwaltung grundsätzlich ohne jede Bedeutung und irrelevant sein muß"84. Eine unterschiedliche arbeitsrechtliche Stellung bestehe im Vergleich zu anderen Bevölkerungsgruppen jedenfalls nicht. Damit wurde die häufig zu beobachtende Benachteiligung von Vertriebenen auf dem Arbeitsmarkt negiert. Während die ZVU zumindest zeitweise versuchte, Politik für ihre Klientel zu betreiben, sahen Aufgaben- und Interessenlage bei der DVAS völlig anders aus: Im Zuge der anvisierten Steigerung der Erwerbstätigenzahlen waren aus Sicht der Arbeitsämter auch Frauen, Jugendliche und Schwerbeschädigte von nahezu gleichrangiger Bedeutung. Wie bei den „Umsiedlern" ergaben sich auch hierbei erhebliche Schwierigkeiten bei der beruflichen Eingliederung.

Die Binnenumsiedlung aufgrund von arbeitsmarktpolitischen Überlegungen beschränkte sich jedoch nicht nur auf die Vertriebenen, sondern konnte auch die einheimische Bevölkerung betreffen. Für die ersten Jahre der SBZ ist vor allem die Arbeitskräftelenkung für den Uranbergbau zu nennen. Auch für andere Wirtschaftsbereiche wie etwa die Landwirtschaft läßt sich eine z.T. umfangreiche Lenkung von Arbeitskräften nachweisen. Einzelne Landesverwaltungen versuchten in dem Zusammenhang entsprechende Verordnungen auszuarbeiten, um dem Umfang und der Durchführung dieser Binnenumsiedlung einen gesetzlichen Rahmen zu geben. So legte beispielsweise die Abteilung Bevölkerungspolitik der

$82 \mathrm{BAB}$, DO 2/1, Bl. 116-123, hier Bl. 117, Denkschrift Chwalczyks vom 14. 4. 1948.

83 Ebenda.

${ }_{84} \mathrm{BAB}, \mathrm{DQ} 2 / 111, \mathrm{Bl}$. 40, Juristische Abt. am 20.3. 1947 an Abt. I. 
Landesregierung Sachsen-Anhalt am 27. April 1949 einen ersten Verordnungsentwurf vor, der die „Umsetzung von Personen aus arbeitsmäßigen Gründen“ nur in bestimmten, klar abgegrenzten Fällen zuließ ${ }^{85}$. Zuerst müßten die „Möglichkeiten einer Arbeitsplatzvermittlung in der Nähe des Wohnortes des Betroffenen oder die Wohnmöglichkeiten für Produktivkräfte in Arbeitszentren [ausge]schöpft“ werden ${ }^{86}$. Die DVdI verhielt sich dagegen in dieser Frage sehr viel zurückhaltender: Man könne nicht davon ausgehen, daß allein mit Hilfe der Binnenumsiedlung die bestehenden wirtschaftlichen Probleme zu lösen seien. Als weitere Instrumentarien nannte die DVdI die Wohnraumbewirtschaftung und die Sozialfürsorge. Zunächst einmal sollten die wirtschaftlichen Schwerpunktgebiete, der jeweilige Arbeitskräftebedarf und die konkrete Lage auf dem Wohnungssektor festgestellt werden. Erst danach sei eine Umsiedlung in Erwägung zu ziehen ${ }^{87}$. Einen Monat später wurde die DVdI noch deutlicher, als sie erklärte, daß „die Frage der Umsetzung von Personen aus arbeitsmäßigen Gründen (Binnenumsiedlung) nicht auf dem Verordnungswege gelöst werden kann" 88 . Die "Wechselbeziehungen zwischen Wirtschaft und Bevölkerung“ seien in der SBZ "recht verschiedenartig und bedürfen jeweils grundlegender Vorarbeiten und Verhandlungen mit allen beteiligten Stellen" 89 . Gleichwohl befürwortete die Innenverwaltung eine zoneneinheitliche Regelung für die „Umsetzung von Personen über die Landesgrenzen“, für die die bestehenden gesetzlichen Bestimmungen aber ausreichen würden. Damit war der Versuch vorerst gescheitert, eine Verordnung zur Arbeitskräftelenkung der Vertriebenen zu beschließen.

Die Führungsgremien der SED befaßten sich kaum mit dem Problem der Eingliederung der „Umsiedler“ in den Arbeitsmarkt der SBZ/DDR. So zeigt die systematische Durchsicht der Protokolle des Zentralsekretariats, des Politbüros und des Kleinen Sekretariats, daß die Führungsspitze der Hegemonialpartei keinerlei Beschlüsse in dieser Angelegenheit faßte. Auch im Zuge des Aufbaus einer zentralen Wirtschaftsplanung war die berufliche Eingliederung der Vertriebenen von untergeordneter Bedeutung. So versuchte die neu gebildete Hauptabteilung Umsiedler und Heimkehrer der DVdI im August 1948 einen „Ergänzungsplan für den Einsatz der Umsiedler bei der Durchführung des 2-Jahresplans“ einzubringen. Eingangs erklärte der Verfasser und ehemalige ZVU-Mitarbeiter, Wilhelm Thiele ${ }^{90}$, daß die Erfüllung dieses Wirtschaftsplanes nicht nur von der Erfassung aller "materieller Reserven und Möglichkeiten, sondern auch von der Mobilisierung der vorhandenen Arbeitskräfte und ihrem zweckentsprechenden Einsatz" abhinge ${ }^{91}$. Um den Mangel an Arbeitskräften in der Industrie zu beheben, sei die

85 BAB, DO 2/58, Bl. 70-72.

86 Ebenda, Bl. 70, Verordnungsentwurf vom 27. 4. 1949, \2, Abs. 1.

87 Ebenda, Bl. 73-77, Entwurf über eine Binnenumsiedlung von der DVdI (HA Verwaltung) vom 25. 5. 1949.

88 Ebenda, Bl. 82, Stellungnahme der HA Verwaltung der DVdI vom 23. 6. 1949 zum Verordnungsentwurf der Landesregierung Sachsen-Anhalt.

89 Ebenda.

90 Thiele war seit 1946 Leiter der Abt. Arbeitseinsatz der ZVU und wechselte noch im Laufe des Jahres 1948 auf den Posten des Bezirksbürgermeisters von Berlin-Mitte. Zwischen 1956 und 1958 war er stellvertretender Oberbürgermeister von Berlin (Ost). SBZ-Handbuch, S. 1042.

91 BAB, DO 2/1, Bl. 199, Richtlinien für die Aufstellung eines Ergänzungsplans für den Einsatz der Umsiedler bei der Durchführung des 2-Jahresplans vom 4. 8. 1948. 
stärkere Eingliederung der Frauen in den Produktionsprozeß und die Erfassung aller „in der Masse der Umsiedler noch vorhandenen Reserven an arbeitsfähigen Menschen notwendig“. Gleichzeitig wies er auf grundlegende Mißstände hin, die einer Realisierung der im Zweijahrplan formulierten Ziele im Wege stehen würden. So seien zahlreiche „Umsiedler“ berufsfremd eingesetzt worden. Die Gründe dafür lagen nach Angaben Thieles vor allem darin, daß entweder entsprechende Beschäftigungsmöglichkeiten am Wohnort des bzw. der Vertriebenen oder ausreichender Wohnraum fehlen würden. Damit hatte er die bereits bekannten Problemkreise wieder angesprochen. Des weiteren hätten - so Thiele weiter - zahlreiche „Umsiedler“ bevorzugt eine landwirtschaftliche Tätigkeit aufgenommen, da hier in der Regel die Versorgung mit Lebensmitteln und Wohnraum besser sei. Diese Hindernisse waren bestimmend gewesen für die Integrationspolitik in den Jahren von 1945 bis 1950 und konnten nie zur Zufriedenheit der staatlichen Behörden aus dem Weg geräumt werden. Aufschlußreich ist aber in unserem Zusammenhang, daß der Vorschlag des früheren ZVU-Mitarbeiters keinerlei Berücksichtigung fand bei der Ausarbeitung des Zweijahrplanes. Auch dies war ein Indiz dafür, daß die SED-Führung eine gesonderte Förderung der „Umsiedler“ im Rahmen der allgemeinen Wirtschaftsplanung ablehnte.

In den wenigen Sitzungen des Kleinen Sekretariats bzw. des Sekretariats des ZK, bei denen die Vertriebenenproblematik auf der Tagesordnung stand, beschränkten sich die Gremienvertreter darauf, einen völlig unverbindlichen Maßnahmekatalog zur Arbeitsmarktintegration der „Umsiedler“ zu verabschieden. So stimmte das Kleine Sekretariat auf seiner Sitzung am 23. Mai 1949 einer Vorlage über „Maßnahmen im Interesse der Umsiedler“ $z^{92}$. Die HVAS wurde aufgefordert, den Arbeitsämtern die Anweisung zu geben, die arbeitsfähigen „Umsiedler“ zu erfassen, welche noch keinen Arbeitsplatz hatten. Darüber hinaus wollte das SED-Gremium über das Ausmaß des fremdberuflichen Arbeitseinsatzes informiert werden, um so eine Lenkung der frei werdenden Arbeitskräfte zu den Industrieschwerpunkten des Landes veranlassen zu können. Als wirtschaftliche Zentren, die aus Sicht der SED Priorität genossen, wurden die im Aufbau befindlichen Werften Mecklenburgs und der Mansfelder Kupferbergbau genannt. Offenkundig hatte sich dort relativ kurzfristig ein Arbeitskräftemangel bemerkbar gemacht. Der Maßnahmenkatalog erstreckte sich jedoch nicht nur auf die Lenkung, sondern auch auf die Mobilisierung zusätzlicher Arbeitskräfte. Neben den bereits erwähnten arbeitsfähigen „Umsiedlern“ ohne Arbeitsstelle waren damit vor allem die arbeitsfähigen „Umsiedlerfrauen“ gemeint, die mit dem Ziel umgeschult werden sollten, „männliche Arbeitsplätze für die Produktionsschwerpunkte freizustellen“. Das Kleine Sekretariat faßte seine Beschlüsse jedoch unverbindlich und ohne zeitliche Vorgaben für die zuständigen Arbeitsämter. Bezeichnend dafür ist auch die Tatsache, daß das SED-Gremium in seinen folgenden Sitzungen auf diesen Beschluß nicht mehr zurückkam.

Einen etwas anderen Stellenwert nahm die Vertriebenengruppe beim Fünfjahrplan ein, den das Politbüro im April 1950 beriet und kurze Zeit später verabschie-

92 SAPMO, DY 30/J IV 2/3/29, Bl. 9. Die folgenden Zitate stammen aus der Anlage zu diesem Tagesordnungspunkt, in: ebenda, Bl. $21 \mathrm{f}$. 
dete ${ }^{93}$. Darin forderte das Politbüro, daß die "Umsiedler" als "gleichberechtigte Staatsbürger in den Produktionsprozeß einzureihen" seien ${ }^{94}$. Darüber hinaus sollten sie bevorzugt mit Einrichtungsgegenständen und Gebrauchsgütern versorgt werden; den arbeitsunfähigen Alten sei zudem eine Sozialrente zu gewähren. Über diese unverbindlichen Absichtserklärungen, die immerhin verbal eine Bevorzugung der Vertriebenen auf dem Arbeitsmarkt in Aussicht stellten, ging das Politbüro jedoch nicht hinaus. Eigentlicher Hintergrund für dieses Entgegenkommen - zuvor waren die "Umsiedler" von der SED-Führung bei den wirtschaftspolitischen Konzeptionen weitgehend ignoriert worden - bildete das Ziel, die Zahl der Erwerbstätigen erheblich zu vergrößern. So sah der Direktivenentwurf des Politbüros für den Fünfjahrplan eine Erhöhung des Beschäftigtenstandes um immerhin ein Drittel vor ${ }^{95}$. Dabei wurden unter anderem die Vertriebenen als eine der Arbeitskraftreserven angesehen, die verstärkt in den Produktionsprozeß einzugliedern waren. Die industriellen Schwerpunkte dieses utopisch anmutenden Programms sollten nach den Vorstellungen der SED folgende Wirtschaftsbranchen sein: Metallurgie, Maschinenbau, Elektrotechnik, Feinmechanik und Optik sowie Chemische Industrie. Ein eigenes arbeitsmarktpolitisches Programm für die „Umsiedler" wurde allerdings auch zu diesem Zeitpunkt nicht beschlossen.

Obwohl Ministerpräsident Otto Grotewohl in seiner Regierungserklärung am 12. Oktober 1949 unter den Sofortmaßnahmen die weitere Eingliederung der "Umsiedler" als eine moralische Verpflichtung hervorgehoben und damit indirekt Handlungsbedarf deutlich gemacht hatte, trat erst elf Monate später das „Gesetz über die weitere Verbesserung der Lage der ehemaligen Umsiedler in der DDR " in $\mathrm{Kraft}^{96}$. Das Gesetz war zwar von der Volkskammer verabschiedet worden, die eigentliche Arbeit hatte aber wieder einmal das SED-Politbüro geleistet ${ }^{97}$. Das Gesetz sah in erster Linie weitere Hilfsmaßnahmen zugunsten der Neubauern in Form von Wohnungsbauförderung und die Vergabe von Krediten an Handwerksbetriebe vor. Gesonderte Beschäftigungsprogramme für arbeitslose „Umsiedler“ enthielt es jedoch auch nicht.

Eine Denkschrift des DWK-Sekretariats im Sommer 1949 machte deutlich, daß auch in Zukunft nicht mit speziellen arbeitsmarktpolitischen Fördermaßnahmen zugunsten der Vertriebenen zu rechnen war ${ }^{98}$. So unterstrichen die Autoren der Denkschrift, die als Informationsmaterial zum SED-Vorsitzenden Wilhelm Pieck gelangte ${ }^{99}$, daß die Arbeitsämter „keine gesonderte Vermittlung für Umsiedler“

93 SAPMO, DY 30/IV 2/2/85, Bl. 89, Protokoll der Sitzung des Politbüros vom 25.4. 1950. Die Direktive für den Fünfjahrplan ist allerdings nur im Arbeitsprotokoll enthalten.

94 Ebenda, Bl. 79-88, hier Bl. 87, Direktive des Politbüros der SED zur Ausarbeitung des Fünfjahrplanes der Volkswirtschaft (1951-1955).

95 Ebenda, Bl. 86.

96 Vgl. dazu Just, Die Integration der Umsiedler, S. 171-173. Das Gesetz ist abgedruckt in: Gesetzblatt der DDR 1950, S. 971-973.

97 Vgl. SAPMO, DY 30/IV 2/2/107, Bl. 21 und 26-30, Protokoll der Sitzung des Politbüros des ZK am 5. 9. 1950.

98 SAPMO, NY 4036/744, Bl. 80-111.

99 Pieck hielt am 12.8. 1949, zwei Tage vor der ersten Bundestagswahl, eine Rede auf einer öffentlichen „Umsiedler“-Versammlung im Zirkus Barlay (Berlin). Die Denkschrift hatte er vermutlich 
durchführen würden ${ }^{100}$. Insgesamt wurde ein positives Bild der zurückliegenden Bemühungen gezeichnet, die Vertriebenen in den ostdeutschen Arbeitsmarkt einzubinden. Ein Vergleich der Zahl der beschäftigten „Umsiedler“ mit der Zahl der im „Arbeitsprozeß stehenden Altbevölkerung “ habe gezeigt, daß die Vertriebenen „ihrem Anteil nach in gleicher Weise wie die Stammbevölkerung in Arbeit gebracht worden sind“" 101 . Nur bei den Frauen würde der Beschäftigtenanteil „etwas unter dem der Altbevölkerung" liegen. Damit habe sich - so die Schlußfolgerungen, die die Autoren der Denkschrift zogen - die „Richtigkeit" der „Umsiedler“Politik in der SBZ gezeigt ${ }^{102}$.

Abschließend sei noch auf die Eigeninitiative der Vertriebenen bei der Arbeitsplatzsuche hingewiesen, die sich in den Akten der Arbeitsverwaltung nicht in angemessenem Umfange wiederspiegelt, aber dennoch nicht unberücksichtigt bleiben sollte. Diese Form der individuellen Arbeitsplatzsuche entzog sich weitgehend der Beobachtung durch die Arbeitsämter, trug aber zweifellos zu einer nicht unwesentlichen Entlastung auf dem Arbeitsmarkt bei. Sie veranschaulicht außerdem die begrenzten Handlungsspielräume sowie die eingeschränkte Wirkungsmacht der staatlichen Verwaltungen in den ersten Nachkriegsjahren. So stellte etwa die Abteilung Umsiedlerbetreuung in Halle Anfang 1946 fest, daß ein großer Teil der Flüchtlinge "sich selbst Arbeit besorgt" habe ${ }^{103}$. Diese Einschätzung verweist darüber hinaus auf die auch für die westlichen Besatzungszonen sowie die frühe Bundesrepublik gemachte Feststellung, daß die Integration der Vertriebenen - nicht nur auf dem Arbeitsmarkt - erst in langfristiger Perspektive und damit erst für die zweite sowie die nachfolgenden Generationen erfolgreich war ${ }^{104}$.

\section{Frauen}

Arbeitsmarktpolitische Programme zugunsten von Frauen unterlagen auch in der SBZ mehreren Zielkonflikten und orientierten sich letztlich sehr stark an den konkreten Erfordernissen der Teilarbeitsmärkte. Insgesamt gesehen ist für die ersten Nachkriegsjahre ein gewisser Anstieg der Frauenerwerbsquote zu beobachten, der dann zu Beginn der fünfziger Jahre wieder abfallen solltei ${ }^{105}$. Die enormen demographischen Veränderungen im Zuge des Zweiten Weltkrieges sowie die damit einhergehende Umstrukturierung der Erwerbsbevölkerung hatten aus Sicht der ostdeutschen Arbeitsverwaltung dazu geführt, daß Frauen in verstärktem Maße in zahlreichen Wirtschaftsbranchen eingesetzt werden sollten, in denen sie

für diesen Zweck beim Sekretariat der DWK in Auftrag gegeben. Die Rede Piecks befindet sich in: SAPMO, NY 4036/440, Bl. 104-118.

100 SAPMO, NY 4036/744, Bl. 85.

101 Ebenda, Bl. 87.

102 Ebenda, Bl. 111.

${ }^{103}$ LA Magdeburg LHA, Rep. K, MinPräs., Nr. 415, Bl. 1, Schreiben der Abt. Umsiedlerbetreuung Halle vom 22. 2. 1946 an den Präsidenten der Provinz Sachsen.

${ }^{104}$ Aus der mittlerweile unübersehbaren Flut an Studien zur westdeutschen Entwicklung z.B.: Haerendel, Berufliche Mobilität von Flüchtlingen; Lüttinger, Integration der Vertriebenen.

$105 \mathrm{Vgl}$. Zank, Wirtschaft und Arbeit, S. 138f. Einen ersten Vergleich der weiblichen Erwerbstätigkeit nach dem Ende des Zweiten Weltkrieges in West- und Ostdeutschland bietet der Sammelband: Budde, Frauen arbeiten. Aus den Publikationen vor 1989/90: Helwig, Frau und Familie. 
zuvor kaum bzw. sehr schwach vertreten waren. Die weibliche erwerbsfähige Bevölkerung wurde daher in gewisser Weise als Manövriermasse zur teilweisen Abdeckung des Arbeitskräftebedarfs angesehen. Dies sollte sich dann mit dem Zurückströmen der entlassenen Kriegsgefangenen Ende der vierziger Jahre erneut ändern. Als weiterer Faktor für den Rückgang der Frauenerwerbsrate dürfte auch die ablehnende Haltung zahlreicher Betriebsleitungen gegenüber der Einstellung von Frauen eine nicht unwesentliche Rolle gespielt haben ${ }^{106}$. Von seiten der Arbeitsämter wurde oft auf dieses Phänomen aufmerksam gemacht; die Durchführung von Kampagnen änderte an diesem Verhalten jedoch wenig. Die Zielkonflikte ergaben sich nicht nur aus den wirtschaftspolitischen Vorstellungen der SED-Führung sowie der DVAS, die auf eine Ausschöpfung des Arbeitskräftepotentials hinausliefen, sondern auch aus dem traditionellen Rollenverständnis der Frau, das in vielfältiger Weise noch erhalten geblieben war. Dieses Spannungsverhältnis hatte unter völlig anderen Ausgangsbedingungen auch während der NSZeit bestanden: Bei dem Versuch, Wirtschaft und Gesellschaft für den „Totalen Krieg“ zu mobilisieren, blieb Deutschland im Vergleich zu einigen alliierten Mächten deutlich zurück ${ }^{107}$.

Zielkonflikte konnten sich auch aufgrund von Anweisungen oder Befehlen der sowjetischen Besatzungsmacht ergeben. So sprachen sich Vertreter der SMADAbteilung Arbeitskraft gegen das Doppelverdienertum aus. Um die Arbeitslosigkeit wirksam bekämpfen zu können, schlugen sie vor, daß „in der Familie immer nur einer arbeiten" solle108. Dabei wurde den Frauen eine untergeordnete Rolle zugewiesen: Der Regelfall sollte die Erwerbstätigkeit des Mannes bleiben. Die ZVAS griff diesen Gedanken auf und beabsichtigte, Doppelverdiener nur noch in Ausnahmefällen zuzulassen. Die Abteilung für Arbeit des Magistrats von Berlin verwies darauf, daß das geplante Vorhaben unvereinbar sei mit den Bestimmungen zur allgemeinen Meldepflicht ${ }^{109}$. Diese legten nämlich fest, daß grundsätzlich die gesamte erwerbsfähige Bevölkerung von den Arbeitsämtern zu registrieren war und damit auch der Arbeitskräftelenkung zur Verfügung stand. Offensichtlich war dieser Zusammenhang entscheidend für das Fallenlassen der Pläne.

Während bei der Ausarbeitung der gesetzlichen Bestimmungen für die Registrierung der arbeitsfähigen Bevölkerung bekanntlich einige Ausnahmen getroffen worden waren, existierten diese in der Anfangsphase noch nicht für die Zwangseinweisung in Arbeit. Die Abteilung Arbeitskraft der SMAD regte dabei die Vorbereitung eines Gesetzes an, das Frauen mit einer bestimmten Anzahl von Kindern vom Arbeitseinsatz explizit befreien sollte ${ }^{110}$. Dagegen wollte die Berliner Zentralverwaltung arbeitsschutzrechtliche Regelungen für Frauen in Form

106 Zank, Wirtschaft und Arbeit, S. 140.

107 Vgl. Winkler, Frauenarbeit im „Dritten Reich“. Vgl. zur Kontroverse über die Mobilisierung nicht erwerbstätiger Frauen in Großbritannien und im Deutschen Reich während des Zweiten Weltkrieges: Milward, Arbeitspolitik und Produktivität; Recker, Nationalsozialistische Sozialpolitik, S. 180-185 und S. 300; Petzina, Soziale Lage der deutschen Arbeiter. Dagegen argumentiert Overy, "Blitzkriegswirtschaft".

108 BAB, DQ 2/2040, Bl. 1, Besprechung am 8.9. 1945 zwischen Vertretern der ZVAS und der SMAD-Abt. Arbeitskraft.

109 BAB, DQ 2/2064, Magistrat Berlin (Abt. für Arbeit) am 17. 10. 1945 an die ZVAS (Abt. III).

$110 \mathrm{BAB}, \mathrm{DQ} 2 / 1, \mathrm{Bl}$. 6, Aktenvermerk über Besprechung mit Herrn Remissow in Karlshorst am 16. 10.1945. 
einer Durchführungsverordnung zum Befehl Nr. 253 herausgeben, der die "gleiche Entlohnung der Frauen, der jugendlichen Arbeiter und der erwachsenen Männer für gleiche Arbeit" gefordert und die DVAS beauftragt hatte, innerhalb von zwei Monaten ein Verzeichnis der Berufe zu erstellen, bei denen Frauenarbeit ausdrücklich ausgeschlossen werden sollte ${ }^{11}$. Die zuständigen Abteilungen der DVAS feilten Anfang Oktober 1947 an einer solchen Durchführungsbestimmung ${ }^{12}$. Eine endgültige Entscheidung konnten und wollten jedoch die Landesverwaltungen nicht abwarten, was wiederum die Einheitlichkeit der arbeitsmarktpolitischen Maßnahmen in der SBZ insgesamt gefährdete. Die einzelnen Landesämter favorisierten in der Regel pragmatische Lösungen. So wurden in Thüringen nach Absprache mit der dortigen SMA Frauen über 46 Jahre vom Arbeitseinsatz befreit ${ }^{113}$. Nachdem der Arbeitskräftebedarf im Laufe des III. Quartals spürbar angestiegen war, hob das thüringische Landesamt diese Bestimmung auf. In der Folgezeit hatte das Landesarbeitsamt die weibliche Altersgruppe zwischen 46 und 60 Jahren wieder zu erfassen und zu vermitteln. Auch wenn bis zu diesem Zeitpunkt kein für die SBZ einheitliches Verbot bestimmter Berufe für Frauen in Kraft getreten war, sah doch die Praxis der Arbeitsvermittlung und -einweisung anders aus. Vor allem Berufe in der Grundstoffindustrie zählten zu den nicht zugelassenen Frauenberufen ${ }^{114}$. Darüber hinaus blieben aufgrund von Überlegungen, die sehr stark vom Arbeitsschutz geprägt waren, einzelne Berufe der Bekleidungsindustrie, der holzverarbeitenden Industrie, der Bau-, aber auch der Nahrungs- und Genußmittelindustrie den Frauen versperrt. Am 8. Januar 1947 veröffentlichte die SMAD schließlich den Befehl Nr. 10, der die Befreiung von Frauen vom Arbeitseinsatz vorsah ${ }^{115}$. Voraussetzung dafür war allerdings, daß die Frauen „selbständig ihren Haushalt führen “ und in ihren Familien Personen zu versorgen hatten, „die nach dem Gutachten deutscher Heilanstalten ständig der Pflege und Bedienung bedürfen“. Darüber hinaus waren Frauen von der Meldepflicht sowie der Möglichkeit zur Zwangseinweisung befreit, wenn sie zwei oder mehr arbeitende Familienmitglieder oder mindestens zwei Kinder unter $15 \mathrm{Jahren}$ hatten. Eine Liste mit Berufen, die mit einem ausdrücklichen Einstellungsverbot versehen war, enthielt dieser Befehl jedoch nicht. Entscheidendes Kriterium blieb die Stellung der Frau im Familienverbund und die damit zusammenhängenden Aufgaben.

$\mathrm{Da}$ die sowjetische Besatzungsmacht eine große Anzahl von arbeitsfähigen Männern für die Demontagetätigkeiten oder die SAG-Betriebe benötigte, diese jedoch nicht in ausreichender Anzahl zur Verfügung standen, versuchte die DVAS/ HVAS, männliche Arbeitskräfte in körperlich leichteren Berufen durch weibliche zu ersetzen. Über den Fortgang dieser Arbeitskräfteumsetzung wollte die SMAD stets genau unterrichtet werden 116 . Im Herbst 1949 verlangte die Abteilung Arbeitskraft von der HVAS, den Arbeitsämtern eine Auflage von rund 30000 „Um-

111 Arbeit und Sozialfürsorge 1 (1946), S. 306.

$112 \mathrm{BAB}, \mathrm{DQ} 2 / 81, \mathrm{Bl}$. 135, Juristische Abteilung am 2. 10.1947 an Abt. I b.

113 SAPMO, DY 30/IV 2/2.027/2, Bl. 25-27, hier Bl. 25, Bericht über Besprechung in Weimar und Halle am 18. und 20. 12. 1946.

114 BAB, DQ 2/1571, Liste der DVAS-Abt. II vom 30. 4. 1946.

$115 \mathrm{BAB}, \mathrm{DQ} 2 / 1503$, Bl. 35. Vgl. Arbeit und Sozialfürsorge 2 (1946), S. 2.

$116 \mathrm{BAB}, \mathrm{DQ} 2 / 2040$, Bl. 146, Aktennotiz über Besprechung mit der SMAD in Karlshorst am 29.6. 1948. 
besetzungen" zu erteilen, die bis zum Jahresende zu erfüllen war. Erst nach längerer Diskussion gelang es einem Vertreter der HVAS, Karlshorst davon zu überzeugen, daß „derartige Auflagen illusorisch seien, da diese Arbeiten vollkommen individuell vorgenommen werden müssen und der Erfolg von der Struktur der Betriebe abhängig sei und nicht vorher bestimmt werden könne"117. Ende September mußte die HVAS einräumen, daß der „Austausch von Männern gegen Frauen noch nicht mit dem gewünschten Erfolg durchgeführt worden ist" 118 . Dies lag nicht nur an den jeweiligen Landesämtern, die für Durchführung der Aktion mit verantwortlich waren, sondern primär an der Tatsåche, daß auf dem Arbeitsmarkt noch freie vollarbeitsfähige Männer zur Verfügung standen, die von den Betrieben bevorzugt angefordert wurden.

Die Arbeitsämter wurden von den Provinzial- bzw. Landesämtern für Arbeit und Sozialfürsorge angewiesen, genaue Angaben zu machen über die Zahl der Frauen mit Kindern bis zu sechs Jahren, der Schülerinnen sämtlicher Lehranstalten, der invaliden Frauen (mit einem Verlust der Erwerbsfähigkeit zu 66,7 Prozent), der „kulturschaffenden“ Frauen sowie der Frauen, die als Freiberufler tätig waren ${ }^{119}$. Dadurch erhoffte sich die Arbeitsverwaltung, einen detaillierten Überblick über die weibliche Bevölkerung zu erhalten, die über die bisherige noch in den Anfängen stehende Arbeitsmarktstatistik hinausreichte. Bei der Zuweisung von weiblichen Arbeitskräften waren nach Angaben des Provinzialamtes für Arbeit und Sozialfürsorge in Halle mehrere Faktoren zu berücksichtigen: In erster Linie sollten "jüngere und ledige oder unabhängige Frauen" eingesetzt werden bzw. solche, "die auf Verdienst angewiesen sind und daher selbst eine Arbeitsvermittlung wünschen“120. Der Einsatz „sozial gebundener Kräfte“ - darunter fielen Mütter mit Kindern bis zu 14 Jahren, Frauen, die für andere Familienangehörige sorgen mußten, sowie Frauen im Alter von 45 bis 50 Jahren, die nicht auf eine Erwerbstätigkeit angewiesen waren - hatte dagegen nur dann zu erfolgen, „wenn es die Bedarfslage erfordert und andere geeignete Kräfte, denen die Arbeitsaufnahme eher zuzumuten ist, nicht mehr vorhanden sind." Das Provinzialamt verlangte vor der beruflichen Einstellung eine sorgfältige Eignungsprüfung, da ansonsten das angestrebte Ziel einer Produktivitätssteigerung in den Betrieben nicht erreicht werden könne: „Wird bei der Auswahl der Kräfte das Moment der Eignung vernachlässigt, dann ist mit einer ausreichenden Leistung nicht zu rechnen, die Wirtschaft hat nicht den erwarteten Nutzen von den Arbeitskräften und die Frauen ihrerseits haben keine Befriedigung in der Arbeit, die eine Grundbedingung für die Leistung darstellt." In Zweifelsfällen sollte deshalb die körperliche Eignung in Zusammenarbeit mit dem Beratungsärzten des zuständigen Arbeitsamtes festgestellt werden. Gleichzeitig sprach sich das Provinzialamt für den verstärkten Ausbau von Kindergärten und Horten aus, um Frauen mit Kindern einen Einstieg in die Arbeitswelt wieder zu ermöglichen. Das sachsen-anhaltische Provinzialamt

$117 \mathrm{BAB}, \mathrm{DQ} 2 / 1950$, Aktenvermerk über eine Besprechung in Karlshorst am 21.9. 1949.

118 BAB, DQ 2/517, HVAS am 29. 9. 1949 an SMAD-Abt. Arbeitskraft.

119 BAB, DQ 2/2066, Provinzialamt für Arbeit und Sozialfürsorge von Sachsen-Anhalt am 4. 1.1946 an die Bezirksämter der Arbeit und Ämter der Arbeit, S. 2.

120 Ebenda, S. 1. 
wagte die durchaus zutreffende Prognose, daß mit zunehmendem Fraueneinsatz diese sozialen Einrichtungen „eine immer größere Rolle spielen“ würden ${ }^{121}$.

Auch die DVAS wies in einer internen Denkschrift auf die zahlreichen Probleme bei der beruflichen Eingliederung von Frauen und deren Benachteiligung gegenüber der männlichen Erwerbsbevölkerung hin ${ }^{122}$. Konkrete Maßnahmen wurden jedoch zunächst auf Länderebene eingeführt. So entwarf etwa das Landesamt für Arbeit und Sozialfürsorge von Mecklenburg-Vorpommern erstmals im Frühsommer 1946 Planungen zur beruflichen Umschulung von Frauen. Dabei machte sich die fehlende Kooperationsbereitschaft von Handwerksmeistern und kleinen mittelständischen Betrieben rasch bemerkbar. Diese konnten sich „vorwiegend wegen der bestehenden Raum- und Materialschwierigkeiten [...] nicht entschließen “, die Umschülerinnen einzustellen ${ }^{123}$. Ein Hindernis stellte außerdem die tarifliche Festlegung des Lohnes dar: Einige Betriebsinhaber weigerten sich offensichtlich, den erwachsenen Umschülerinnen ein höheres Entgelt zu zahlen als den Lehrlingen. Die Hauptabteilung Frauenfragen beim FDGB-Bundesvorstand mußte in dem Zusammenhang bei Gewerkschaftskonferenzen generell Klagen von Frauen zur Kenntnis nehmen, daß ,in völlig ungenügendem Maße die Angleichung der Frauenlöhne und die Verwirklichung des Grundsatzes - gleicher Lohn für gleiche Leistung - geschieht "124. Die Realisierung des SMAD-Befehls scheiterte oftmals am hinhaltenden Widerstand nicht nur der Betriebsleitungen, sondern auch der Betriebsräte. Die Arbeitsverwaltung war bei Kontrollen auf die Kooperation der Betriebe angewiesen, was keineswegs immer gewährleistet war. Besonders schwierig gestaltete sich die Überprüfung bei den SAG-Betrieben ${ }^{125}$, die sich den deutschen Verwaltungen nicht nur in dieser Frage fast vollständig entzogen. Daraus ergab sich die paradoxe Situation, daß die sowjetische Besatzungsmacht einen entsprechenden Befehl ("Gleiche Entlohnung für gleiche Arbeit") erlassen hatte, für dessen Umsetzung den ostdeutschen Arbeitsämtern und vor allem der DVAS kaum Machtbefugnisse zur Verfügung standen.

Nach offiziellen sowjetischen Angaben waren die Wirtschaftszweige mit einem sehr hohen Frauenanteil Ende 1946: das Schneidereigewerbe (84,2 Prozent), die Tabakindustrie (75,6 Prozent), die Textilindustrie (70,7 Prozent), die Musikinstrumenten- und Spielwarenindustrie (60 Prozent) sowie die Nahrungsmittelindustrie (59,7 Prozent) ${ }^{126}$. Der Anteil der abhängig beschäftigten Frauen betrug insgesamt gesehen bereits 44,5 Prozent. Da der Bericht keine weiteren, vor allem differenzierteren Angaben enthält, können die genannten Zahlen nur eine Tendenz angeben: So ist auch die Mitteilung mit Vorbehalten zu sehen, zehn Prozent der im Bergbau beschäftigten Arbeitskräfte seien Frauen. Von deutscher Seite wurden

121 Ebenda, S. 2.

$122 \mathrm{BAB}, \mathrm{DQ} 2 / 1571$, Denkschrift der DVAS o.D. (vermutlich Frühjahr 1946).

123 BAB, DQ 2/2064, Bericht der DVAS über die Reise nach Schwerin am 18.6. 1946, S. 1.

124 SAPMO, DY 30/IV 2/17/26, Bl. 6, FDGB-Vorstand, HA Frauenfragen (Friedel Malter), am 1. 8. 1946 an PV der SED, Abt. Frauen (Käthe Kern).

125 Ebenda, Bl. 115, Vermerk von Lisa Ullrich vom 7. 1. 1947 über eine Besprechung mit Oberstleutnant Nasarow in Karlshorst.

126 P. Schaposchnikow, Beseitigung der Arbeitslosigkeit und Frauenbeschäftigtenquote, in: ,Tägliche Rundschau' vom 16. 11. 1946, zitiert nach: SAPMO, DY 30/IV 2/17/25, Bl. 145. 
diese Prozentangaben einen Tag später im ,Neues Deutschland' bestätigt ${ }^{127}$. Auffallend ist die Tatsache, daß die Berufsgruppen etwas anders gefaßt wurden und die Angaben geringfügig voneinander abwichen. In der Tendenz gingen sie aber in dieselbe Richtung: Schwerpunkte der Frauenbeschäftigung waren das Gaststättengewerbe und vor allem die Textil- und Bekleidungsindustrie. Quantitativ von Bedeutung erschienen außerdem die Landwirtschaft (60 Prozent) sowie der Beruf der Hausgehilfen mit insgesamt 318000 Beschäftigten, in dem fast ausschließlich Frauen arbeiteten (98 Prozent).

Zur Verbesserung der Verwaltungsarbeit bildete die HVAS-Abteilung Erfassung und Arbeitslenkung im Laufe des Sommers 1948 ein eigenständiges Frauenreferat, in dem zukünftig „alle grundsätzlichen Fragen der Erfassung und Lenkung der weiblichen Arbeitskräfte" bearbeitet werden sollten ${ }^{128}$. Die Berliner Hauptverwaltung schlug den Landesarbeitsämtern vor, ihre Verwaltungsstruktur dementsprechend anzupassen. Diese organisationstechnische Maßnahme rückte zwar die Frauenerwerbstätigkeit etwas stärker in den Mittelpunkt der Verwaltungsarbeit ${ }^{129}$, die positiven Ergebnisse, die davon ausgehen sollten, blieben jedoch zunächst noch aus. Nicht nur das Frauenreferat der HVAS, sondern auch die innerhalb der SED organisierten Frauen hatten sich mittlerweile unter Anleitung der Abteilung Frauen des SED-Parteivorstandes zu einem Fürsprecher der Belange beschäftigter Frauen entwickelt. Im Zuge der Ausarbeitung des Zweijahrplanes forderte eine in Chemnitz tagende Landeskonferenz von 500 „werktätigen Frauen der SED“ am 16. August 1948, daß „Möglichkeiten zur Entlastung der bereits werktätigen und noch in den Produktionsprozeß einzubeziehenden Frauen gesucht und gefunden werden "130. Dazu gehörten zunächst einmal Auf- und Ausbau von sozialen Einrichtungen: die Schaffung von betrieblichen Wochenkinderheimen, Nähstuben, Waschküchen sowie die Einrichtung von Verkaufsmöglichkeiten innerhalb des Betriebes. Der FDGB unterstützte dieses Anliegen auf seiner Sozialpolitischen Arbeitstagung am 27./28. September $1948^{131}$.

Aufgrund des engen finanz- und haushaltspolitischen Spielraumes entwickelte sich vermutlich die Forderung nach einem umfassenden Auf- und Ausbau von betrieblichen Kindergärten und ähnlichen sozialen Einrichtungen zu einem langfristigen Ziel, das vorerst zurückgestellt werden mußte. Auf ausdrückliche Anweisung des Obersten Chefs der SMAD, Marschall Wassili D. Sokolowski, wurde die arbeitsmarktpolitische Förderung der Frauenerwerbstätigkeit in eine etwas andere Richtung gelenkt: Sie sollte mittelfristig mit den Umschulungsplänen verbunden werden bzw. in diesen aufgehen ${ }^{132}$. Einzelne Landesverwaltungen versuchten parallel dazu, durch die Verbesserung der betrieblichen Gesundheitsfürsorge Frauen mit Kleinkindern die Ausübung ihres Berufes zu ermöglichen. Die

127 ,Neues Deutschland' vom 17. 11. 1946, zitiert nach: SAPMO, DY 30/IV 2/17/25, Bl. 148.

128 BAB, DQ 2/2064, Krüger am 6.7. 1948 an die Landesarbeitsämter in Erfurt, Schwerin, Halle und Potsdam.

${ }^{129}$ Die Einrichtung des Frauenreferats bei den Landesarbeitsämtern ging zügig voran. Anfang Juli besaß das LAA Sachsen ein entsprechendes Fachreferat. Vgl. BAB, DQ 2/1762, Bericht der HVASAbt. I b über die Amtsleitertagung am 9./10. 7. 1948 in Mittweida, S. 1.

130 SAPMO, DY 30/IV 2/17/24, Bl. $134 \mathrm{f}$.

131 BAB, DQ 2/144, Bl. 43-58, hier Bl. 58, Anlage Nr. 2 zum Tagungsprotokoll.

132 $\mathrm{BAB}, \mathrm{DQ} 2 / 1948$, Aktenvermerk Donaus über eine Besprechung in Karlshorst am 20. 8. 1948. 
Abteilung Gesundheitswesen im brandenburgischen Ministerium für Arbeit und Sozialwesen favorisierte in dem Zusammenhang den Ausbau von Säuglingskrippen in großen Krankenhäusern und Landesanstalten sowie in den Betrieben. Sie bat die Kreisgesundheitsämter des Landes, gemeinsam mit dem DFD und FDGB einen Plan über die Aufteilung der Kinderkrippen innerhalb ihres Zuständigkeitsbereiches aufzustellen ${ }^{133}$. Dahinter stand jedoch nicht in erster Linie das Bestreben, die Gleichberechtigung von Mann und Frau in der Arbeitswelt voranzutreiben, sondern die Erfüllung der Wirtschaftspläne sowie die weitere Ausschöpfung des Arbeitskräftepotentials. Das Ziel der Arbeitsverwaltung, die Frauenerwerbsquote zu steigern, wurde in der westdeutschen Presse zum Teil heftig kritisiert. Besonders eine Textpassage des brandenburgischen Rundschreibens rief dabei Empörung hervor: „Wenn man berechnet, daß eine Frau in den besten Jahren im Abstand von 3 Jahren 4 Kinder bekommt, bedeutet das einen Arbeitsausfall von 14 Jahren. Das steht im Widerspruch zum 2 Jahresplan. "134 In der Tageszeitung ,Der Tag' wurde vor dem Rückfall in die Zeit des Hochkapitalismus während der zweiten Hälfte des 19. Jahrhunderts gewarnt und auf den Mißbrauch der Frauenund Kinderarbeit aufmerksam gemacht ${ }^{135}$. Durch die Veröffentlichung in der westdeutschen Presse war die Berliner Hauptverwaltung aufgeschreckt worden. Die Kritik der HVAS entzündete sich jedoch weniger am Inhalt der brandenburgischen Initiative, als vielmehr am Wortlaut: „Der Zweck, nämlich besondere Einrichtungen für schwangere Frauen und stillende Mütter im Produktionsprozeß zu schaffen, hätte mit einer wesentlich glücklicheren Begründung erreicht werden können." 136 Der Minister für Arbeit und Sozialwesen Brandenburgs Schwob bedauerte den Vorfall137. Während Brack der Frage nachgehen wollte, auf welche Weise die dienstliche Mitteilung in die westliche Presse gelangen konnte und dabei Verschwörungstheorien entwickelte ${ }^{138}$, versuchte die Hauptverwaltung Gesundheitswesen die mittlerweile aufgeheizten Gemüter besonders bei der HVAS zu beruhigen ${ }^{139}$. Diese Auseinandersetzung machte unter anderem auch deutlich, wie stark der sich ausweitende „Kalte Krieg“ nahezu sämtliche politischen Subsysteme zu erreichen und zu prägen vermochte.

Die arbeitsmarktpolitischen Initiativen zugunsten der Eingliederung von Frauen in das Erwerbsleben blieben zwischen Kriegsende und DDR-Gründung relativ spärlich und in ihren Folgewirkungen außerordentlich begrenzt. Es gab zwar Programme zum Aufbau von Kindergärten und ähnlichen betrieblichen Einrichtungen, deren Verwirklichung jedoch an den oben genannten Gründen scheiterte. Weitgehend ergebnislos verlief außerdem das Ansinnen einzelner Ar-

133 BAB, DQ 2/963, Rundschreiben des Ministers für Arbeit und Sozialwesen von Brandenburg am 26. 10. 1948 an alle Gesundheitsämter, DFD-Kreisleitungen und Frauensekretariate bei den FDGB-Kreisleitungen.

134 Ebenda.

135 ,Der Tag' vom 18. 5. 1949, Zeitungsartikel: „Die Frauen und Mütter in der Produktion“, zitiert nach: BAB, DQ 2/963.

$136 \mathrm{BAB}, \mathrm{DQ} 2 / 963$, HVAS-Präsident Brack am 29. 6. 1949 an die HV Gesundhcitswesen (Prof. Linser).

137 Ebenda, Schwob am 24. 6. 1949 an die HVAS.

138 Ebenda, Brack am 29. 6. 1949 an die HV Gesundheitswesen (Prof. Linser).

139 Ebenda, HV Gesundheitswesen (Dr. Winter) am 15. 8. 1949 an die HVAS (Brack). 
beitsämter, Richtsätze für den Frauenanteil in den Betrieben festzulegen ${ }^{140}$. Die Entscheidungskompetenz über die Einstellung von Arbeitskräften lag in diesem Zeitraum letztlich bei den Betriebsleitern, die dabei andere Faktoren berücksichtigen mußten: Auftragslage, Produktionsauslastung, Absatzmärkte, Belieferung mit Rohstoffen, aber auch das konkrete Arbeitskräfteangebot vor Ort etc. Somit hatten die Pläne zur Ausweitung der weiblichen Erwerbsbevölkerung, die im Zusammenhang mit dem Zweijahrplan von der HVAS ausgearbeitet wurden, zunächst nur den Charakter einer Absichtserklärung ${ }^{141}$. Doch auch die Verbesserung der Rahmenbedingungen (Kindergärten etc.) ließ sich nicht in dem von der HVAS erhofften Maße erreichen. $\mathrm{Zu}$ diesen die Frauenarbeit unterstützenden Faktoren sollte nach den Vorstellungen der DVAS/HVAS sowie des DFD auch die Einführung eines bezahlten Hausarbeitstages ${ }^{142}$ gehören, der bis 1949 jedoch nicht zonal einheitlich gesetzlich verankert werden konnte. Aus wirtschaftspolitischen aber auch ideologischen Überlegungen heraus zog sich diese Debatte in die Länge und konnte erst 1952 abgeschlossen werden: Dabei wurde dann den alleinstehenden Frauen ohne Kindern der Rechtsanspruch auf einen Hausarbeitstag verwehrt ${ }^{143}$. Bis zu diesem Zeitpunkt blieb es Aufgabe der Länder, eine Regelung herbeizuführen.

\section{Jugendliche}

Die berufliche Ausbildung von Jugendlichen ${ }^{144}$ sowie deren Eingliederung in die einzelnen Teilarbeitsmärkte gehörte nicht von Anfang an zu den vordringlichen Aufgaben der ZVAS/DVAS. So blieb es der am 7. März 1946 von der SMAD lizensierten FDJ ${ }^{145}$ zunächst überlassen, auf diesem Politikfeld aktiv zu werden: Der Entwurf des Zentraljugendausschusses, das Organisationskomitee der FDJ, enthielt unter anderem die Forderung nach einer „planmäßige[n] Lenkung der jugendlichen Arbeitskräfte für solche Berufe, die eine Zukunft haben" ${ }^{146}$. Konkrete arbeitsmarktpolitische Überlegungen schlossen sich daran jedoch nicht an, vielmehr handelte es sich um eine allgemein gehaltene Forderung, die Bestandteil eines Katalogs von „Grundrechte[n] der jungen Generation“ war. Zusammen mit den bürgerlichen Blockparteien CDU und LDP, dem FDGB, den Kirchen, der

140 So hatte sich etwa der Beratungsausschuß des Arbeitsamtes Brandenburg für einen Frauenanteil zwischen 15 und 20\% ausgesprochen. Vgl. BAB, DQ 2/2063, Protokoll der Sitzung des Beratungsausschusses des Arbeitsamtes Brandenburg vom 21. 3. 1949.

141 Vgl. Arbeit und Sozialwesen. Mitteilungsblatt des Ministeriums für Arbeit und Sozialwesen Thüringens Nr. 1 vom Juli 1949, S. 2, zitiert nach: ThHStA, Land Thüringen, Ministerium für Wirtschaft und Arbeit, Bd. 3597, Bl. 276.

$142 \mathrm{Vgl}$. zu den historischen Vorläufern im „Dritten Reich“ sowie die unterschiedliche Entwicklung in den beiden deutschen Staaten nach 1945/49: Sachse, Ein "heißes Eisen“.

${ }^{143}$ Sachse, Ein "heißes Eisen“, S. 258. Ob das Vorhaben in der SBZ am Widerstand der SMAD scheiterte, wie Sachse behauptet (S. 257), muß bezweifelt werden. Die sowjetische Besatzungsmacht wollte vermutlich die Regelung des Hausarbeitstages vielmehr den Betrieben überlassen. Anstelle einer Verordnung sollten daher tarifliche bzw. betriebliche Vereinbarungen getroffen werden. Vgl. SAPMO, DY 30/IV 2/17/31, Bl. 9, Auszug aus dem Geschäftsbericht des FDGB 1946, S. 114.

${ }^{44} \mathrm{Vgl}$. dazu auch die Darstellung in: Vergleich von Bildung und Erziehung; Zank, Wirtschaft und Arbeit, S. 112-119.

${ }_{1+5}$ Mählert, Die Freie Deutsche Jugend, S. 93-95.

146 BAB, DQ 2/1847, Entwurf des Zentraljugendausschusses (Organisationskomitee der FDJ) vom 24. 4. 1946, S. 3. 
Volkssolidarität, dem zentralen Frauenausschuß und den Jugendämtern gründete die FDJ am 18. August 1946 das „Werk der Jugend“, das auf maßgebliche Anregung der SED zurückging, und das sich zur Aufgabe setzte, die Jugendarbeitslosigkeit zu bekämpfen sowie die Mängel in der Berufsausbildung zu beheben ${ }^{147}$. Obwohl die Durchführung von Arbeitseinsätzen durchaus eingeplant wurde, nahm man doch rasch von den Plänen Abstand, eine Arbeitsdienstpflicht einzuführen. Die arbeitsmarktpolitische Bedeutung dieser Initiative, mit deren Hilfe die SED vermutlich die Blockpolitik stärken und die gerade ins Leben gerufene Jugendorganisation politisch aufwerten wollte, muß indessen gering veranschlagt werden ${ }^{148}$. Dies hing mit dem schleppendem Organisationsaufbau sowie der permanenten Finanznot zusammen. Darüber hinaus war rasch deutlich geworden, daß für Fragen der Beschäftigung, Entlohnung und Ausbildung andere Institutionen zuständig waren: die wirtschaftlichen Zentralverwaltungen in Berlin und die entsprechenden Landes- bzw. Provinzialämter sowie die sowjetische Besatzungsmacht.

Es war zunächst die sowjetische Besatzungsmacht, die die Frage des beruflichen Nachwuchses in der SBZ aufwarf und dazu den Befehl Nr. 254 am 20. August 1946 veröffentlichte. Dieser hatte die Sicherstellung der Ausbildung qualifizierter Arbeiter und Angestellten auf dem Gebiet der berufstechnischen, landwirtschaftlichen und medizinischen Schulen zum Ziel ${ }^{149}$. Die Präsidenten der Länder und Provinzen erhielten den Auftrag, zum 1. September ein "Netz von Schulen [aufzubauen] und die Zahl der Schüler in den einzelnen Berufen" festzusetzen. Die Fertigstellung entsprechender Räumlichkeiten sollte zu Beginn des Schuljahres 1946/47 abgeschlossen werden. In einer Anlage befanden sich genaue Zahlenangaben, unterteilt nach den einzelnen Ländern, den unterschiedlichen Schultypen sowie den jeweiligen Berufsgruppen ${ }^{150}$. Die SMAD legte den Schwerpunkt in ihrem Befehl eindeutig auf die berufstechnischen Schulen: Hier sollten im Schuljahr 1946/47 insgesamt 378500 Berufsschüler aufgenommen werden. Für die landwirtschaftlichen Schulen waren insgesamt 12600 Schüler vorgesehen, für die medizinischen Schulen nochmals 2900 . Diese Vorgaben entsprachen vermutlich dem sowjetischen Interesse nach Facharbeitern, aber wohl auch dem allgemeinen Bedarf an qualifizierten Arbeitern von seiten ostdeutscher Betriebsleitungen. Die Frage des beruflichen Nachwuchses war des öfteren Gegenstand von Besprechungen zwischen Vertretern der DVAS und der Abteilung Arbeitskraft in Karlshorst. Dabei wiesen die SMAD-Vertreter unter anderem auf die „Überalterung der Arbeiterschaft in den wichtigsten Industriezweigen " hin ${ }^{151}$. Die Arbeitsverwaltung wurde aufgefordert, der Ausbildung von Jugendlichen, deren „materielle[r] Sicherstellung" und wohnlichen Unterbringung "größte Aufmerksamkeit" entgegenzubringen.

Der Aufforderung der sowjetischen Besatzungsmacht, die berufliche Ausbildung von Jugendlichen zu forcieren, um den Arbeitskräftebedarf langfristig mit

147 Mählert, Die Freie Deutsche Jugend, S. 181.

148 Ebenda, S. $182 \mathrm{f}$.

${ }^{149}$ BAB, DQ 2/1503, Bl. 58.

150 Ebenda, Bl. 59-61.

$151 \mathrm{BAB}, \mathrm{DQ} 2 / 67, \mathrm{Bl} .24$, Aktennotiz über Besprechung in Karlshorst am 22. 10. 1946. 
abdecken zu können, stand die Praxis zahlreicher SAG-Betriebe diametral entgegen. Im Herbst 1946 häuften sich die Meldungen, nach denen sowjetische Generaldirektoren nicht nur die Einstellung von Lehrlingen ablehnten, sondern teilweise sogar die Entlassung von bereits beschäftigten Lehrlingen vornehmen wollten ${ }^{152}$. Die DVAS bat daraufhin die Abteilung Arbeitskraft in Karlshorst, die angekündigte Entlassungswelle zu verhindern und den Einstellungsstopp wieder rückgängig zu machen. Die Berliner Zentralverwaltung unterstrich die Bedeutung der Berufsausbildung in den SAG-Betrieben: Angesichts des großen Mangels an Lehrstellen sei es „sowohl aus wirtschaftlichen als auch aus politischen Gründen nicht tragbar, wenn die SAG's sich von der Lehrlingsausbildung ausschließen wollten." Karlshorst schloß sich offensichtlich dieser Meinung an. Die DVAS wurde ermächtigt, den Landesverwaltungen mitzuteilen, daß die Vorgehensweise der betreffenden SAG-Betriebsleitungen "gesetzlich ungültig" sei153. Die Lehrlinge waren demzufolge sogar berechtigt, bei den Arbeitsgerichten Einspruch gegen ihre Entlassung einzulegen. Allerdings mußte sich erst noch in der Praxis erweisen, inwieweit die Stellungnahme der SMAD-Abteilung Arbeitskraft Einfluß auf die SAG-Betriebe haben konnte. Bei der Durchführung sowjetischer Befehle, die die Bereitstellung von Arbeitskräften für Vorhaben der Besatzungsmacht betrafen, hatte sich gezeigt, wie einflußlos die Karlshorster Abteilung mitunter war. Dies bestätigte sich auch in den folgenden Monaten. So berichtete etwa das thüringische Ministerium für Arbeit und Sozialwesen, daß die SAG-Betriebe „sehr einseitig und betriebsgebunden eingestellt sind und die Tendenz dahin geht, nur Fachkräfte für den eigenen Betrieb bzw. sogenannte Spezialisten in kurzen Lehrgängen heranzubilden" ${ }^{154}$. Bei entsprechenden Überprüfungen sei keinerlei Entgegenkommen von seiten der sowjetischen Generaldirektoren, aber auch der deutschen Betriebsleiter erkennbar gewesen; neue Lehrstellen seien nicht bereitgestellt worden. Die DVAS wurde von dem Ministerium in Erfurt mehrmals aufgefordert, bei der SMAD in Karlshorst eine Erhöhung der Lehrstellen in den SAG-Betrieben zu erreichen ${ }^{155}$. Die DVAS reichte diese Bitten an die Abteilung Arbeitskraft in Karlshorst weiter und betonte dabei, daß die SAG-Betriebe bei der Lehrlingseinstellung „vorbildlichst vorangehen müssen" 156 .

Ab dem Frühjahr 1948 trat die Debatte über die Berufsausbildung in eine neue Phase ein. Den Hintergrund dafür bildete eine Verordnung vom 9. Oktober 1947, die sich ausschließlich auf die Ausbildung von Industriearbeitern in den Berufsschulen beschränkt hatte ${ }^{157}$. Diese Verordnung sah unter anderem die Bildung eines Zentralausschusses für Berufsausbildung vor, der die weitere Arbeit koordinieren sollte. Dieses Gremium bestand lange Zeit nur auf dem Papier, und die

152 BAB, DQ 2/1908, DVAS am 9. 10. 1947 an die SMAD-Abt. Arbeitskraft (Morenow).

15.3 Vgl. BAB, DQ 2/1908, Rundschreiben der DVAS vom 28. 10.1947 an alle Länder.

${ }^{15+} \mathrm{BAB}, \mathrm{DQ} 2 / 137, \mathrm{Bl}$. 309, Ministerium für Arbeit und Sozialwesen des Landes Thüringen am 2. 1. 1948 an die DVAS. In Thüringen gab es zu diesem Zeitpunkt 44 SAG-Betriebe mit insgesamt 49741 Beschäftigten; darunter befanden sich 1681 Lehrlinge sowie 117 Umschüler. Die Ausbildung in den Lehrwerkstätten der SAG's wurde als vergleichsweise gut bis sehr gut eingestuft.

$155 \mathrm{BAB}, \mathrm{DQ} 2 / 137, \mathrm{Bl}$. 313, Ministerium für Arbeit und Sozialwesen des Landes Thüringen am 2. 1. 1948 an die DVAS.

156 Ebenda, Bl. 317, DVAS am 16. 3. 1948 an SMAD-Abt. Arbeitskraft.

157 Arbeit und Sozialfürsorge 2 (1947), S. 473-476. 
DVAS mußte sich von seiten des FDGB-Bundesvorstandes ermahnen lassen, die Verordnung endlich umzusetzen ${ }^{158}$. Als besonders drängendes Problem schätzte die DVAS-Abteilung II, die sich Anfang März in die Diskussion einschaltete, die Abdeckung des Bedarfs an Lehrlingswohnheimen ein: So befänden sich in einzelnen Bezirken zahlreiche Jugendliche, welche „die noch offenen Lehrstellen in Städte[n] und Industriegebiete[n] nicht antreten können, da dort keine Unterk[ü]nft[e] vorhanden “ seien ${ }^{159}$. Hierbei überschnitten sich jedoch die Zuständigkeitsbereiche der DVAS-Abteilung „Ausbildung und Umschulung“ mit den kommunalen Wohnungsämtern sowie mit den Jugendämtern ${ }^{160}$. Nach Auffassung der ostdeutschen Arbeitsverwaltung gehörte es zu den Aufgaben der Landesjugendämter, für die Errichtung und Erhaltung dieser Wohnheime Sorge zu tragen $^{161}$. Solche Fragen überließ die sowjetische Besatzungsmacht weitgehend den deutschen Verwaltungen: Ihr Interesse galt der beruflichen Nachwuchsausbildung und der Erfüllung der von ihr vorgegebenen Auflagen. Die SMAD kritisierte in erster Linie die Schwerpunktsetzung der Berufsausbildung, die mit den Zielen der Besatzungsmacht oftmals nicht übereinstimmte. So wurde etwa moniert, daß die Berufsschulen im Raum Senftenberg zwar 4000 Jugendliche ausbilden würden, aber nur 56 für die dortigen Braunkohlengruben ${ }^{162}$. Einzelnen Berufsschullehrern wurde vorgehalten, sie hätten „von der notwendigen Nachwuchslenkung für den Bergbau keine Ahnung“. Die DVAS-Vertreter konnten in diesem Fall allerdings nachweisen, daß der Bedarf an qualifizierten Bergleuten im Braunkohletagebau in der Tat gering war.

Die DWK registrierte im Frühjahr 1948 einen steigenden Fachkräftemangel in der SBZ, insbesondere an Ingenieuren nahezu aller Fachrichtungen. In Anlehnung an das sowjetische Vorbild schlug die Hauptverwaltung Wirtschaftsplanung den Aufbau neuer Hochschulen vor, die einem Großbetrieb angegliedert werden und sich auf ein Spezialgebiet beschränken sollten ${ }^{163}$. Das „Monotechnikum“ war nach diesen Planungen unter anderem vorgesehen für die Leuna-Werke sowie die Maxhütte in Unterwellenborn. Die unmittelbare Nähe zum Betrieb schien zwei Ziele zu garantieren: Zum einen die praxisnahe Ausbildung und zum anderen geringfügige Kosten, da „die befähigsten Ingenieure“ des betreffenden Betriebes als Dozenten heranzuziehen waren. Unkosten entstanden nur in Form von Sachmitteln für die Ausstattung von Unterrichtsräumen sowie durch den partiellen Ausfall der Dozenten für die betriebliche Produktion, der sich jedoch in Grenzen hal-

158 BAB, DQ 2/371, Bl. 101, FDGB-Bundesvorstand (HA 3) am 16. 2. 1948 an die DVAS.

159 Ebenda, Bl. 132, Aktenvermerk der Abt. II vom 5. 3. 1948.

160 Vgl. zum Aufbau der Jugendämter in der SBZ: Hoffmann, Jugendämter im Wandel. Zur Jugendfürsorge in der SBZ/DDR sowie in vergleichender Perspektive: Rudloff, Öffentliche Fürsorge, S. 207-209 und S. $214 \mathrm{f}$.

161 BAB, DQ 2/371, Bl. 132, Aktenvermerk der DVAS-Abt. II vom 5. 3. 1948.

162 Von den 4000 Auszubildenden ließen sich u.a. 1000 Jugendliche für den Beruf als Hausangestellter ausbilden, 200 für die Bekleidungsindustrie, 300 für kaufmännische Berufe und 256 für die Landwirtschaft. BAB, DQ 2/371, Bl. 120f., hier Bl. 120, Aktenvermerk über den Besuch Koreschkows (SMAD) am 30. 3. 1948 .

$163 \mathrm{BAB}, \mathrm{DC}$ 15/63, Bl. 2, HV Wirtschaftsplanung (Kromrey) am 5. 5. 1948 an den DWK-Vorsitzenden Heinrich Rau. In der Sowjetunion war in der ersten Hälfte der zwanziger Jahre diese spezialisierte Form der Technischen Hochschule entstanden. Die Bezeichnung "Monotechnikum“ stammt offensichtlich auch von dort. 
ten sollte (zwei bis vier Stunden pro Woche). Die Hauptverwaltung Wirtschaftsplanung ging davon aus, daß auf diese Weise ,in zwei bis drei Jahren schon ein erster guter Stamm von Fachingenieuren verfügbar sein wird“. Diese Pläne gingen der HVAS offenbar etwas zu weit. Sie konzentrierte sich weniger auf die Ausbildung eines akademischen Nachwuchses, sondern auf die betriebliche Lehrlingsausbildung, die langfristig den Facharbeiterbedarf abdecken sollte164. Die Gemeinsamkeit bei beiden Programmen bestand in der betrieblichen Einbettung der Aus- und Weiterbildung. Während sich die Hauptverwaltung Wirtschaftsplanung auf die Spezialistenrekrutierung konzentrierte und weitgehend kostenneutrale Planungen entwarf, widmete sich die HVAS einer quantitativ größeren Gruppe. Letzteres war weitaus kostenintensiver und sollte nach den Vorstellungen der Arbeitsverwaltung auf die Länder- und Gemeindehaushalte abgewälzt werden.

$\mathrm{Da}$ der Auf- und Ausbau der Berufsschulen nicht die erhofften Fortschritte machte, schnitt die SMAD wiederholt die Frage der institutionellen Zuständigkeiten an. So wurde von seiten eines sowjetischen Vertreters die Gründung einer eigenständigen Verwaltung ins Gespräch gebracht, die sich aus Mitarbeitern der HVAS und der Zentralverwaltung für Volksbildung zusammensetzen sollte ${ }^{165}$. Fritz Selbmann, der stellvertretender DWK-Vorsitzender und Leiter der Hauptverwaltung Industrie war, lehnte dies ab und bekräftigte, daß die Aufgaben der Berufsausbildung "eindeutigst" bei der HVAS liegen. Die dortige Abteilung II sollte statt dessen personell vergrößert werden 166 . Gleichzeitig begannen DWK und die beteiligten Hauptverwaltungen (HVAS und DVV) damit, Nachwuchspläne für die einzelnen Wirtschaftsbereiche auszuarbeiten. Nachdem diese Pläne bei den Gewerkschaften durchgesickert waren, wandte sich beispielsweise die IG Metall an die HVAS, um auf die Situation der Jugendlichen in der metallverarbeitenden Industrie aufmerksam zu machen und auf eine Verbesserung der Berufsausbildung in diesem Bereich zu drängen ${ }^{167}$. Der Vorsitzende des Fachausschusses Bau wies auf die Nachwuchsprobleme in der Bauwirtschaft hin und plädierte dafür, die Bauindustrie als Schlüsselindustrie aufzuwerten, um dadurch die Ausstattung mit Sachmitteln, aber auch die Zuteilung von Arbeitskleidung und Schuhwerk sowie die Entlohnung insgesamt zu verbessern ${ }^{168}$. Die Ankündigung von staatlichen Unterstützungsmaßnahmen bei der betrieblichen Berufsausbildung hatte somit bei den Gewerkschaften und den noch zugelassenen Verbänden Begehrlichkeiten geweckt. Unabhängig von der zunehmenden Umwandlung der verbliebenen Interessenorganisationen zu Transmissionsriemen der SED, die Mitte 1948 keineswegs vollständig abgeschlossen war, wurden etwa von seiten der Gewerkschaftsleitungen doch nach wie vor eigene Interessen vorgetragen. Auf

${ }^{164}$ BAB, DC 15/63, Bl. 1, Entwurf der HVAS-Abt. II vom 20. 5. 1948.

${ }^{165}$ BAB, DQ 2/371, Bl. 47f., hier Bl. 48, Aktenvermerk vom 2.6. 1948 über Besprechung mit Koreschkow.

166 Ebenda.

$167 \mathrm{BAB}, \mathrm{DQ} 2 / 371, \mathrm{Bl} .90$, Zentralvorstand der IG Metall (Abt. Jugend) am 6.7. 1948 an die HVAS. Der FDGB-Bundesvorstand sprach sich auf seiner Sozialpolitischen Arbeitstagung am 27./28.9. 1948 generell für einen Ausbau der Berufsschulen, Lehrwerkstätten sowie die Vergrößerung des Lehrstellenangebots aus. Vgl. BAB, DQ 2/144, Bl. 58, Entschließung der Sozialpolitischen Arbeitstagung am 27./28. 9. 1948.

168 BAB, DQ 2/371, Bl. 66f., Vorsitzender des Fachausschusses Bau (Pisternik) am 23. 7. 1948 an die HV Wirtschaftsplanung (Radelt). 
der anderen Seite zeigten sich erste Konsequenzen bei der bereits erkennbaren Bevorzugung von Betrieben der Grundstoffindustrie: So verwies der Vorsitzende des Fachausschusses Bau explizit darauf, daß die staatliche Förderung des Bergbaus und der Metallindustrie die Berufe dieser Industriezweige gegenüber der Bauwirtschaft „anziehender" gemacht habe ${ }^{169}$.

Ende Juli 1948 existierten im Land Brandenburg insgesamt 32 betriebliche Berufsschulen, deren Gründung größtenteils auf Initiative der DWK bzw. der beteiligten Hauptverwaltungen zurückzuführen war ${ }^{170}$. Darunter befanden sich etwa die Braunkohlenwerke in Senftenberg, das Hüttenwerk in Hennigsdorf sowie die Volkswerft Thälmann in Brandenburg/Havel. Die Erfüllung des Nachwuchsplanes 1948/49 ging in Brandenburg nur äußerst schleppend voran: Der relative Anteil der männlichen Auszubildenden lag gegenüber den Vorgaben bei 37,1 Prozent, bei den weiblichen Auszubildenden betrug er 31,2 Prozent ${ }^{171}$. Mit der Vorbereitung des Halbjahrplanes wurde auch die Berufsausbildung in die wirtschaftliche Gesamtplanung verstärkt eingebunden; Vertreter der SMAD-Abteilung Arbeitskraft wiesen bei ihren Treffen mit Mitarbeitern der DWK bzw. der HVAS öfters auf die Notwendigkeit einer engen Verzahnung hin ${ }^{172}$.

Eine neue qualitative Ebene erreichte die Berufsausbildung mit dem Zweijahrplan, da die HVAS nunmehr gezwungen war, den Aufbau von Berufsschulen in den Ländern zu koordinieren und den Nachwuchsplan nach einheitlichen Kriterien für die gesamte SBZ aufzustellen. Um die weitere Vorgehensweise besser aufeinander abstimmen zu können, lud die Berliner Hauptverwaltung Vertreter der Landesministerien zu einer Arbeitsministerkonferenz am 12. Oktober 1948 in Berlin ein, an der auch zwei Mitarbeiter der SMAD-Abteilung Arbeitskraft teilnahmen. Präsident Brack machte einleitend auf die Tatsache aufmerksam, daß für die Durchführung des Nachwuchsplanes geeignetes Personal in den Landesverwaltungen fehle ${ }^{173}$. Anschließend faßte der Mitarbeiter der HVAS-Abteilung II Häuseler die bisherige Entwicklung der beruflichen Ausbildung kurz zusammen und gab einen Ausblick über die bevorstehenden Aufgaben. Auch er betonte das Ziel, eine betriebs- und praxisnahe Ausbildung zu verwirklichen. Dieses lasse sich aber nicht sofort realisieren: „Da die gegenwärtigen Verhältnisse und wohl auch nicht in absehbarer Zeit es gestatten [sic], für den Nachwuchs in den Betrieben selbst die erforderlichen Ausbildungsplätze bereitzustellen, wird es notwendig sein, Lehrwerkstätten zu schaffen, um die im Nachwuchsplan geforderten Lehrstellenbesetzungen zu erfüllen. "Überlegungen, diese Lehrwerkstätten bei den Berufsschulen einzurichten, stellten seiner Meinung nach nur eine Übergangslösung dar; die betriebliche Verbundenheit müsse letztlich garantiert werden. Bis zum 1. September hatten in der SBZ bereits 99 Betriebs-Berufsschulen ihre Tätig-

169 Ebenda, Bl. 66.

170 BAB, DQ 2/371, Bl. 77, Liste der HVAS (HA II) vom 28. 7. 1948.

171 Der Nachwuchsplan 1948/49 sah 17795 männliche und 15235 weibliche Auszubildende vor. Am 31. 7.1948 waren dagegen nur 6602 männliche und 4752 weibliche Auszubildende gemeldet. BAB, DQ 2/371, Bl. 55, Liste der HVAS (HA II).

$172 \mathrm{BAB}, \mathrm{DQ} 2 / 1535, \mathrm{Bl} .114$, Aktennnotiz über Besprechung mit Morenow in Karlshorst am 20.8. 1948.

173 BAB, DQ 2/1303, Bl. 67-73, hier Bl. 67, Bericht über die Arbeitsministerkonferenz am 12.10. 1948. 
keit aufgenommen. Die im Plan vorgesehene Zahl von 440 Schulen, die zum 31. Dezember 1949 funktionsfähig sein sollten ${ }^{174}$, schien etwas zu hoch gegriffen zu sein: Ungeklärt war nämlich nicht nur die konkrete Anbindung der Berufsschulen an die Betriebe, sondern auch die Finanzierung der benötigten Sachmittel sowie des einzustellenden Lehrpersonals. Hier hakten die Ländervertreter dann auch nach. Der brandenburgische Minister für Arbeit und Sozialwesen, Fritz Schwob, bemängelte etwa, daß sowohl die entsprechende Verordnung als auch der Nachwuchsplan „viel zu spät und zudem noch mangelhaft zur Kenntnis“ der Landesministerien gelangt seien ${ }^{175}$. Darüber hinaus hätte die HVAS für zahlreiche Berufe immer noch keine „Berufsbilder" erstellt. Präsident Brack wies in seinem Schlußwort die Kritik an seiner Verwaltung zurück: „Wenn [der Plan] reichlich spät fertiggestellt werden konnte, so liegt es daran, weil wir auf die Mitarbeit der Länder angewiesen waren, die leider hier und da noch zu wünschen übrig läßt. Ein Plan kann nur aufgestellt werden, wenn man die Zahlen der Länder zur Verfügung hat." 176

Auf der nächsten Arbeitsministerkonferenz am 9./10. Dezember 1948 teilte Häuseler den unterschiedlichen Nachwuchsbedarf in einzelnen Wirtschaftsbranchen mit ${ }^{177}$. Seinen Ausführungen war zu entnehmen, daß besonders im Bergbau der Bedarf nicht gedeckt werden konnte. In der Landwirtschaft und in der Glasindustrie standen nicht genügend Lehrstellen zur Verfügung; in der Metallindustrie lag bei einzelnen Berufen ein Facharbeitermangel vor. Als besonderes Problem stellte der HVAS-Mitarbeiter das fehlende Interesse der volkseigenen Betriebe dar, verstärkt Frauen einzustellen. An diesen wenigen und unsystematischen Angaben wurde zweierlei deutlich: Zum einen ließ sich der konkrete Bedarf der Betriebe an auszubildenden Jugendlichen nicht so eindeutig und vor allem nicht so rasch feststellen. Zum anderen konnten Betriebe nicht ohne weiteres angehalten werden, mehr Lehrstellen zur Verfügung zu stellen. Beides zusammen trug dazu bei, daß der Nachwuchsplan nicht die von der HVAS erhoffte Wirkung entfalten konnte. Eine zufriedenstellende Lösung konnte auch im Frühjahr 1949 noch nicht gefunden werden. Die HVAS berichtete, daß sich die Zuteilung von Ausbildungsplätzen nach wie vor als sehr problematisch erweise: „Hier stoße man bei den Betrieben und im Handwerk auf große Schwierigkeiten. Selbst die volkseigenen Betriebe entziehen sich der Verpflichtung, Jugendliche auszubilden. ${ }^{1}{ }^{178}$ Aus diesem Grunde wurde erwogen, Auflagen für die Betriebe zur Einstellung von Lehrlingen einzuführen.

Nachdem der Zentralausschuß für Berufsausbildung auf seiner Sitzung am 15. März 1949 in Dresden den Nachwuchsplan 1949 abschließend beraten und genehmigt hatte, lag nun eine verbindliche Grundlage für alle Länder der SBZ vor ${ }^{179}$. Dabei gingen die beteiligten Ressorts von einer Gesamtzahl an Schulabgängern in

\footnotetext{
174 Ebenda, Bl. 68.

175 Ebenda.

176 Ebenda, Bl. 69.

$177 \mathrm{BAB}, \mathrm{DQ} 2 / 1303, \mathrm{Bl}$. 26-34, hier Bl. 30f., Sitzungsbericht über die Arbeitsministerkonferenz am 9./10. 12. 1948 .

178 BAB, DQ 2/2063, Bericht der HVAS-Abt. I a über die Amtsleitertagung am 5./6. 3. 1949 in Ludwigslust, S. 3.

179 BAB, DQ 2/963, Erläuterungen der HVAS-Abt. II zum Nachwuchsplan 1949.
} 
Höhe von 295000 aus, deren berufliche Ausbildung sichergestellt werden mußte. Der Ausschuß für Sozialpolitik beim Deutschen Volksrat unterstützte seinerseits die vorgesehene Lehrlingsausbildung am 14. April 1949 nachträglich ${ }^{180}$. Da jedoch die Deutsche Zentralverwaltung für Volksbildung keine genauen Angaben über die Zahl der zu erwartenden Schulabgänger machte und darüber hinaus einige Hauptverwaltungen den in ihrem Zuständigkeitsbereich registrierten Bedarf an Nachwuchskräften nicht an die HVAS weitergaben ${ }^{181}$, war eine weitere Überarbeitung des Nachwuchsplanes unumgänglich. Gleichzeitig hatte die DWK offenbar angekündigt, die Lehrlingsausbildung in den volkseigenen Betrieben sowie in den SAG-Betrieben gesondert regeln zu wollen ${ }^{182}$. Vor allem letzteres war bekanntlich am hinhaltenden Widerstand der sowjetischen Generaldirektoren stets gescheitert. Kurz zuvor hatte der Leiter der DWK-Hauptverwaltung Industrie, Fritz Selbmann, die Vereinigungen Volkseigener Betriebe (VVB) beauftragt, die ihnen unterstehenden Betriebe anzuweisen, eine "gründliche Überprüfung vorzunehmen, inwieweit die betrieblichen Möglichkeiten zur Aufnahme von auszubildenden Lehrlingen erschöpft sind oder inwieweit neue Möglichkeiten hierfür geschaffen werden können" 183 .

Ende Mai 1949 lagen für alle Länder Nachtragspläne vor, die für die volkseigenen Betriebe sowie die SAG-Betriebe relevant waren. Während der Anteil der vorhandenen Lehrstellen an den Planvorgaben in Thüringen immerhin bei 54 Prozent lag ${ }^{184}$, konnte das Arbeitsministerium in Potsdam für Brandenburg nur eine Planerfüllungsquote von etwa 15 Prozent melden ${ }^{185}$. Unterschiede ergaben sich auch bei der Errichtung der betrieblichen Berufsschulen: So hatte die Landesverwaltung Thüringen insgesamt 58 Schulen aufgebaut, in denen 5473 Jugendliche ausgebildet wurden. Die HVAS kritisierte in dem Zusammenhang, daß die einzelnen Schulen nicht gleichmäßig ausgelastet seien. In Thüringen hatten - so der HVAS-Mitarbeiter Häuseler auf der Arbeitsministerkonferenz am 31. Mai 1949allein elf Schulen eine Schülerzahl von unter 50, darunter befanden sich offenbar auch Ausbildungseinrichtungen mit „18, 20 und 23 Schülern" 186 . Vergleichbare Probleme bei der effizienten Auslastung der Berufsschulen registrierte die Arbeitsverwaltung in Sachsen, Sachsen-Anhalt und Brandenburg. In Mecklenburg-Vorpommern hatte die vornehmlich landwirtschaftliche Prägung des Landes Auswirkungen auf das dortige Ausbildungssystem: 54 der 65 gemeldeten betrieblichen Berufsschulen seien nur im primären Sektor tätig187. Die HVAS plädierte daher für die Einführung einer „Richtziffer“ von 100 Schülern pro Berufsschule, die nur in Ausnahmefällen unterschritten werden durfte, wobei die Zahl nicht unter 50 fallen sollte. Das bedeutete letztlich die Zusammenlegung der Berufsaus-

$180 \mathrm{BAB}, \mathrm{DQ} 2 / 1504$.

$181 \mathrm{BAB}, \mathrm{DQ} 2 / 2063$, Niederschrift über die Besprechung der HVAS-Abteilungen I a und I b am 3. 5. 1949, S. 3 .

$182 \mathrm{BAB}, \mathrm{DQ} 2 / 1763$, Protokoll über die Amtsleitertagung am 13./14. 5. 1949 in Chemnitz, S. 16.

$183 \mathrm{BAB}, \mathrm{DQ} 2 / 963$, DWK (HV Industrie) am 11.5.1949 an alle VVB.

184 Ebenda, HVAS-Abt. I b am 25. 5. 1949: Nachtragsplan zum Nachwuchsplan 1949 in Thüringen.

185 Ebenda, HVAS-Abt. I b am 25. 5. 1949: Nachtragsplan zum Nachwuchsplan 1949 in Brandenburg.

$186 \mathrm{BAB}, \mathrm{DQ} 2 / 1303, \mathrm{Bl} .12-23$, hier Bl. 16, Bericht der HVAS über die Arbeitsministerkonferenz am 31. 5. 1949.

187 Ebcnda. 
bildung von mehreren volkseigenen Betrieben; nicht jeder Betrieb konnte demzufolge seine eigene Berufschule behalten. Ursache für diesen Sparkurs waren die bei der Aufstellung der Landeshaushalte vorgenommenen Kürzungen im Schul- und Ausbildungswesen. Den Arbeitsministern der Länder war es nicht gelungen, ihre Kollegen in der Landesregierung von der Notwendigkeit zu überzeugen, Finanzmittel für diesen Ausbildungsbereich bereitzustellen. Die Landesregierungen erklärten den Aufbau der Berufsschulen vielmehr zu einer Aufgabe der Berliner Hauptverwaltungen, die damit auch die finanzielle Versorgung zu übernehmen hätten.

Anfang Juni 1949 schaltete sich die FDJ nach längerer Pause wieder in die Diskussion ein. In einer Vorlage für das III. Parlament der Jugendorganisation wurden die Mängel bei der Berufsausbildung hervorgehoben, die man darauf zurückführte, daß die „dem Plan zugrunde liegenden Zahlen der in Lehrstellen zu vermittelnden Jugendlichen und der vorhandenen Lehrstellen ungenau" seien ${ }^{188}$. Die FDJ sprach sich für eine erhebliche Stärkung des Zentralausschusses für Berufsausbildung aus, der sich bisher als weitgehend bedeutungsloses Gremium erwiesen hatte. Der Zentralausschuß sollte eine zentrale Koordinierungsfunktion übernehmen, d.h. „mehr als bisher alle an den Fragen für Berufsausbildung interessierten Verwaltungen und Organisationen zusammenfassen und in regelmäßigen Abständen alle diesbezüglichen Fragen beraten ". Darüber hinaus sollte der Zentralausschuß das Recht erhalten, Betriebe und deren Lehrwerkstätten mit dem Ziel einer Ausweitung des Ausbildungsprogramms zu überprüfen. Anders als die DWK-Hauptverwaltungen sowie die Landesregierungen befürwortete die FDJ eine erhebliche finanzielle Beteiligung der Betriebe an der Berufsausbildung. Mit diesen Vorschlägen stand die Jugendorganisation jedoch alleine da; sie wurden von seiten der staatlichen Verwaltungen nicht aufgegriffen. Es fällt im übrigen auf, $\mathrm{da} ß$ die Massenorganisationen in dieser Debatte eine nur marginale Position einnahmen. Dabei ist vor allem die Konzeptions- und Tatenlosigkeit des FDGB bemerkenswert.

Bei der betrieblichen Berufsausbildung erwiesen sich erneut die Betriebe als entscheidender Bremsfaktor. Nicht nur Arbeitsämter, sondern auch Kreisverwaltungen der SED bestätigten dies indirekt. So forderte die Abteilung Arbeit und Sozialfürsorge der SED-Kreisverwaltung Greifswald die Einführung von Strafmaßnahmen gegen Betriebsinhaber, die sich weigerten, zusätzlich Lehrlinge einzustellen. Bei wiederholter Weigerung sollte sogar mit der Enteignung gedroht werden ${ }^{189}$. Die HVAS bestätigte die vorgetragene Kritik und wies darauf hin, daß die Betriebe von den zuständigen Arbeitsämtern verpflichtet werden könnten, "laufend eine Barleistung bis zur vollen Höhe des Lehrlingslohnes zu erstatten“, falls sie ihrer Einstellungsverpflichtung nicht nachkommen sollten ${ }^{190}$. Zum wiederholten Male hatte sich ein Konfliktfeld zwischen den Zentral- und Landesverwaltungen auf der einen und den Betrieben auf der anderen Seite aufgetan. Dieses ergab sich aus den unterschiedlichen Anweisungen aus Berlin, die teilweise wider-

${ }^{188} \mathrm{BAB}, \mathrm{DQ} 2 / 963$, Vorlage an das III. Parlament der FDJ (1.-4.6.1949), S. 1.

$189 \mathrm{BAB}, \mathrm{DC}$ 15/63, Bl. 24, SED-Kreisverwaltung Greifswald am 10.6. 1949 an die Plankontrolle der DWK (Scholz).

190 Ebenda, Bl. 26f., Beyer am 16. 8. 1949 an die SED-Kreisverwaltung Greifswald. 
sprüchlich waren: Im vorliegenden Falle handelte es sich um die Forderung nach Ausdehnung des Lehrstellenangebots und um die gleichzeitig erhobene Forderung nach kurzfristiger Produktivitätssteigerung. Durch den SMAD-Befehl Nr. 234 waren die Betriebe aufgefordert worden, die Arbeitsproduktivität zu steigern und notfalls auch Entlassungen vorzunehmen. Das implizit enthaltene Gebot der betrieblichen Rentabilität und des sparsamen und effizienten Faktoreinsatzes widersprach auf den ersten Blick den durch die Berufsausbildung neu anfallenden Kosten. Unabhängig von diesem Zielkonflikt, den die DWK und ihre Hauptverwaltungen zu keinem Zeitpunkt auflösen konnten, hatte sich gezeigt, daß die Verstaatlichung der Wirtschaft zwar weiter vorangeschritten und der staatliche Zugriff auf die Betriebe zum Teil erheblich verstärkt worden war. Dennoch blieben auch für die volkseigenen Betriebe nicht unerhebliche Handlungsspielräume bestehen, die etwa bei der Abwehr zentraler Vorgaben deutlich wurden. Die Interessen der Betriebsleiter waren nicht zwangsläufig deckungsgleich mit denen der Arbeitsverwaltung; die von oben angeordnete Vermehrung der Lehrstellen in den Betrieben wurde eben nur unvollkommen und sehr verzögert umgesetzt. Bei der DWK und der Arbeitsverwaltung machte sich daher eine gewisse Ratlosigkeit breit, da entsprechende Sanktionsmittel zur Durchsetzung der Nachwuchspläne nicht zur Verfügung standen.

Die HVAS bevorzugte letztlich den Einsatz von positiven Sanktionsmitteln: Mit Hilfe finanzieller Anreize sollte die Bereitschaft der Betriebe zur Einstellung von Lehrlingen gefördert werden ${ }^{191}$. Eine entsprechende Vorlage, die von der DWK jedoch nicht verabschiedet wurde, sah vor, daß für die Errichtung von zusätzlichen Ausbildungsplätzen 48 Millionen DM aus gesperrten Mitteln der Sozialversicherungsanstalten zur Verfügung gestellt werden sollten. Der angestrebte Wandel der arbeitsmarktpolitischen Instrumente vollzog sich jedoch nur langsam. Die DWK hatte bisher auf die schlechte Entwicklung bei der Berufsausbildung stellenweise mit der Bildung neuer Gremien, wie des Zentralausschusses für Berufsausbildung, oder der Verlagerung von Zuständigkeiten reagiert. Dies geschah vermutlich in enger Abstimmung mit der SED-Führung, die im Sommer 1949 der Deutschen Zentralverwaltung für Volksbildung mehr Kompetenzen gegenüber der HVAS einräumte, die bis dahin alleine verantwortlich gewesen war ${ }^{192}$.

Kurz vor Beginn des neuen Ausbildungsjahres am 1. September 1949 hatte sich die Situation in der SBZ leicht verbessert: Die Zahl der eingerichteten Betriebsberufsschulen sowie der Lehrstellenplätze war weiter angestiegen ${ }^{193}$, ohne aber die Planvorgaben erreicht zu haben. Außerdem hatte die Aufforderung der HVAS, daß mehrere Betriebe sich bei der Berufsausbildung zusammenschließen

191 Ebenda, Bl. 5f., Vorlage der HVAS vom 16. 8. 1949.

$192 \mathrm{BAB}, \mathrm{DQ} 2 / 1764, \mathrm{Bl}$. 8f., Bericht über dic Arbeitsbesprechung der Abt. I b mit den Leitern der Abt. I b in den Ländern und den Leitern der Landesarbeitsämter am 9. 8. 1949.

193 Vgl. BAB, DQ 2/517, Aufstellung des Ministeriums für Arbeit und Sozialwesen des Landes Sachsen vom 25. 8. 1949 über die Betriebsberufsschulen, die ab 1.9. 1949 ihren Unterricht fortsetzen oder neu aufnehmen; ebenda, Aufstellung der Landesverwaltung von Sachsen-Anhalt über die Betriebsberufsschulen, die ab 1.9. 1949 ihren Unterricht fortsetzen oder neu aufnehmen; ebenda, Ministerium für Arbeit und Sozialwesen des Landes Thüringen am 25. 8. 1949 an die HVAS mit einer Liste der Betriebsberufsschulen; ebenda, Liste der Landesverwaltung Brandenburgs vom 27. 8. 1949 über die Betriebsberufsschulen, die ab 1.9. 1949 ihren Unterricht fortsetzen oder neu beginnen. 
sollten, durchaus Früchte getragen. Zumindest in der sächsischen Textilindustrie war diese Reaktion zu beobachten ${ }^{194}$; von anderen Wirtschaftszweigen und den übrigen Ländern liegen dagegen keine Angaben vor.

\section{Arbeitseinsatz von Strafgefangenen}

Die von der SED- und DWK-Führung angestrebte Mobilisierung aller Arbeitskraftreserven für die Arbeitswelt, die mit der Vorbereitung des Zweijahrplanes zunehmend an Bedeutung gewann, erfaßte auch Personengruppen, die bis dahin nicht im Mittelpunkt des Interesses der Arbeitsverwaltung gestanden hatten. Dazu zählten unter anderem die Strafgefangenen, deren Arbeitskraft nach den Vorstellungen der HVAS begrenzt nutzbar gemacht werden sollte. Der Kontrollratsbefehl Nr. 3 vom 17. Januar 1946 enthielt zwar einige wenige Vorschriften, die die Arbeitsämter zur Zwangseinweisung berechtigten ${ }^{195}$, dennoch war auch hier die Ausarbeitung von entsprechenden Richtlinien erforderlich. Dies konnte nur in enger Absprache mit der Deutschen Justizverwaltung (DJV) erfolgen, die bis Anfang der fünfziger Jahre die Zuständigkeit für den Strafvollzug besaß. Der Arbeitseinsatz von Strafgefangenen wurde dadurch begünstigt, daß die DJV ihrerseits Reformbestrebungen verfolgte, die darauf hinausliefen, für eine bestimmte Gefangenengruppe eine „Bewährungsarbeit“ mit dem langfristigen Ziel der Vorbereitung auf die Resozialisierung nach Beendigung der Haftzeit einzuführen. Diese Reformüberlegungen gingen teilweise auf Vorläufer in der Weimarer Republik zurück, wurden nach 1945 in der SBZ von der Leitung der Justizverwaltung wieder aufgegriffen und weiter entwickelt ${ }^{196}$. Für die DJV kam eine praktische Überlegung hinzu: Der Arbeitseinsatz von Strafgefangenen bot die Möglichkeit, die Haftanstalten der SBZ zu entlasten, die mittlerweile erheblich überbelegt waren.

Bereits im Herbst 1946 hatte das sächsische Landesarbeitsamt eine Aussprache über den Einsatz von Gefangenen mit der dortigen Justizverwaltung geführt, die sich gegenüber dem Vorhaben ganz aufgeschlossen zeigte ${ }^{197}$. In Sachsen kamen dafür offensichtlich 500 Häftlinge in Frage. Voraussetzungen für den Arbeitseinsatz waren eine gesicherte Unterbringung und die Aufsichtsführung, die noch nicht hinreichend geklärt werden konnten. Außerdem mußte eine Regelung bei der Entlohnung gefunden werden. Vertreter der DVAS, die auf diesem Wege zusätzliche Facharbeiter gewinnen wollten, sprachen sich dafür aus, „die Angelegenheit des Gefangeneneinsatzes auch in den anderen Ländern und Provinzen zu klären und in die Wege zu leiten" 198.

194 BAB, DQ 2/517, Aufstellung des Ministeriums für Arbeit und Sozialwesen des Landes Sachsen vom 25. 8. 1949 über die Betriebe, die sich zur Errichtung einer Betriebsberufsschule zusammengeschlossen haben.

195 Vgl. Kontrollratsbefehl Nr. 3 vom 17. 1. 1946, Ziffer 16, Satz 1 und Ziffer 18, in: Arbeit und Sozialfürsorge 1 (1946), S. $8 \mathrm{f}$.

196 Vgl. dazu sowic generell zur Position der DJV in dieser Angelegenheit: Wentker, Justiz in der SBZ/ DDR, S. 204-222.

${ }^{197}$ BAB, DQ 2/2064, Aktenvermerk der DVAS-Abt. I über Besprechung mit dem Landesarbeitsamt Sachsen am 6./7. 12. 1946, S. 4.

198 Ebenda. 
Die DVAS-Abteilung I b legte am 20. März 1947 einen ersten Richtlinienentwurf für den Arbeitseinsatz von Strafgefangenen vor ${ }^{199}$. In diesem wurde einleitend der Aspekt der Strafrechtsreform und der enge Zusammenhang mit der Arbeitsmarktpolitik betont: „Der feste Rahmen einer Gemeinschaft produktiv Schaffender ist dabei der beste Helfer [für die Resozialisierung]. Außerdem soll dem Bedürfnis der Wirtschaft nach Arbeitskräften und vor allem nach Facharbeitern Rechnung getragen werden." 200 Allerdings konnten nur Verurteilte mit einer geringen Haftstrafe in den Genuß dieser Regelung kommen, auf die im übrigen kein Rechtsanspruch bestand. Die Höchstgrenze der Haftzeit als Inklusionskriterium blieb noch offen ${ }^{201}$. Aufschlußreich war der erläuternde Zusatz, daß die Straftaten „nur aus Notlage oder Leichtsinn, nicht aber aus asozialen Beweggründen" erfolgt sein dürfen. Damit wurde ein erheblicher Interpretationsspielraum für die Bewilligung von Bewährungsarbeit geschaffen. Die DVAS-Abteilung, die die Unterschiede zur Arbeitseinweisung der übrigen Bevölkerung hervorhob, wollte gleichzeitig verhindern, daß den Betrieben, in denen Strafgefangene eingesetzt wurden, Wettbewerbsvorteile gegenüber anderen Unternehmen erwuchsen. Daher sollte der Arbeitgeber nicht nur ausführlich über den Einsatz jedes Gefangenen berichten, sondern auch einen noch festzulegenden Prozentsatz des Nettolohnes an die Justizbehörde abführen. Bei ungenügender Arbeitsleistung oder schlechter Führung konnte - so sah es der Entwurf vor - das Arbeitsamt die Arbeitseinweisung wieder rückgängig machen und bei der Justizverwaltung die Abbüßung der Haftstrafe beantragen 202. Der Entwurf, der umgehend an die DJV weitergeleitet wurde, war offensichtlich nicht mit der Juristischen Abteilung der DVAS abgesprochen ${ }^{203}$. Damit hatten sich nicht zum ersten Mal Abstimmungsschwierigkeiten innerhalb der Berliner Zentralverwaltung ergeben: Die Juristische Abteilung drängte darauf, bei der Ausarbeitung von Rechtsvorschriften mit eingeschaltet $z u$ werden. Die Abteilung I b rechtfertigte das eigene Vorgehen mit dem Hinweis, daß eine Beteiligung der Juristischen Abteilung vorgesehen war, sobald sich „das ganze Problem in seiner Entwicklung [...] in einem fortgeschrittenen Stadium befindet“204. Abteilungsleiter Kreil hielt es für unangebracht, „daß eine Fachabteilung selbständig überhaupt keine Schriftsätze abfassen und Verhandlungen im vorbereitenden Stadium führen dürfte, ohne vorher jeden Schriftsatz erst der Juristischen Abteilung vorzulegen" 205 . Eine solche Praxis würde die inhaltliche Arbeit der DVAS in einem erheblichen Umfange einschränken. Schließlich lenkte die Juristische Abteilung in der Auseinandersetzung ein und unterstrich,

199 BAB, DQ 2/2480.

200 Ebenda, S. 1.

201 DVAS-Mitarbeiter Siegfried Tscheschner unterschied in dem Zusammenhang zwischen vier Gefangenengruppen: „Leichtbestrafte und langfristig Verurteilte mit bestimmten Bedingungen durch Bcwährungsarbeit, und Gefangene in den Strafanstalten durch Arbeit in den Gefängnissen oder in Gefangenenkommandos." Die Bewährungsarbeit sollte seiner Meinung nach zunächst nur für die erste Gruppe eingeführt werden, blieb aber den drei restlichen Gruppen nicht grundsätzlich vorenthalten. Vgl. Siegfried Tscheschner: Aufgaben der Arbeitslenkung im Strafvollzug, in: Arbeit und Sozialfürsorge 2 (1947), S. $375 \mathrm{f}$.

$202 \mathrm{BAB}, \mathrm{DQ} 2 / 2480$, Richtlinienentwurf vom 20. 3. 1947, S. $3 \mathrm{f}$.

${ }^{203}$ Ebenda, Juristische Abt. (Helm) am 18. 4. 1947 an Abt. I (Kreil).

${ }^{204}$ Ebenda, Aktennotiz der Abt. I b vom 22. 4. 1947.

${ }^{205}$ Ebenda, Abt. I b am 22. 4. 1947 an die Juristische Abt., S. 1. 
daß die Bearbeitung von Gesetzentwürfen anderer Abteilungen „in erster Linie unter juristischen Gesichtspunkten" erfolgen werde 206 .

Am 9. Juli 1947 lag der Entwurf einer gemeinsamen Anweisung der DJV und der DVAS vor, der im wesentlichen aus der Feder der Justizverwaltung stammte ${ }^{207}$. Diese regelte im einzelnen den Arbeitseinsatz von Leichtbestraften (Bewährungseinsatz), langfristig Verurteilten, Gefangenenkommandos sowie von Gefangenen in Strafanstalten. Strittig war nunmehr die Frage, ob der Entwurf als Anweisung oder als Verordnung zu veröffentlichen war. Während die DJV für den Verordnungsweg plädierte, sprach sich die DVAS-Abt. I b aus Zeitgründen dagegen aus: Verordnungsentwürfe mußten der SMAD zugeleitet und von ihr genehmigt werden. Diese verfahrenstechnischen Überlegungen führten letztlich zu einer nochmaligen Verzögerung bei der Veröffentlichung. Ende Juli einigten sich beide Zentralverwaltungen auf die Verabschiedung von gemeinsamen Richtlinien, die inhaltlich kaum vom Entwurf der DJV vom 9. Juli abwichen $^{208}$. Nachdem beide Zentralverwaltungen dem Richtlinienentwurf zugestimmt hatten, konnte dieser am 1. September 1947 im Amtlichen Organ ,Arbeit und Sozialfürsorge' veröffentlicht werden ${ }^{209}$. Von entscheidender Bedeutung für die Arbeitsverwaltung war die darin enthaltene gesetzliche Regelung, die den Arbeitsämtern die Aufgabe zuwies, den ausgewählten Strafgefangenen Arbeitsplätze zuzuweisen.

Die Landesarbeitsämter wurden von der DVAS beauftragt, über die konkrete Durchführung der Richtlinien zu berichten. Darüber hinaus war der Arbeitseinsatz von Strafgefangenen Thema der Arbeitsministerkonferenzen sowie der Amtsleitertagungen. So berichtete ein Vertreter der mecklenburgischen Landesverwaltung Anfang Januar 1948, daß im nördlichsten Land der SBZ etwa 600 Bewährungsarbeiter beschäftigt seien ${ }^{210}$. Aus den anderen Ländern lagen dagegen noch keine Zahlenangaben vor. Ausführliche Berichte trafen erst im Laufe des Frühjahrs 1948 allmählich bei der Berliner Zentralverwaltung ein. Dies hing vor allem damit zusammen, daß die Landesarbeitsämter mit den Landesjustizverwaltungen in Verhandlungen eintreten mußten, um die in Frage kommenden Haftanstalten sowie den genauen Personenkreis festzulegen. Der Erfolg der Aktion hing somit vom Kooperationswillen nicht nur der Landesjustizministerien, sondern auch der Strafanstalten und der Strafgefangenen ab. Anfang Februar vereinbarte etwa das thüringische Ministerium für Arbeit und Sozialwesen mit der Generalstaatsanwaltschaft in Gera, in fünf Gefängnissen (Gera, Eisenach, Untermaßfeld, Ichtershausen und Gräfentonna) „eine individuelle Werbung" durch die Arbeitsämter durchzuführen 211 . Dabei war auch vorgesehen, Gefangene mit längeren Haftstrafen sowie rechtskräftig Verurteilte, die noch nicht in die Strafanstalten eingewiesen waren, für den Arbeitseinsatz zu gewinnen. Aufgrund des bestehen-

\footnotetext{
206 Ebenda, Juristische Abt. am 24. 4. 1947 an Abt. I b., S. 1.

207 Ebenda, Abt. I b am 10. 7. 1947 an die Juristische Abt. mit Anlage.

208 Ebenda, Entwurf vom 28.7. 1947.

209 Arbeit und Sozialfürsorge 2 (1947), S. 376-378.

210 BAB, DQ 2/1537, Niederschrift über den Verlauf der Arbeitstagung der DVAS (Abt. I b) in Leipzig am 6./7. 1. 1948, S. 26.

211 ThHStA, Land Thüringen, Ministerium für Wirtschaft und Arbeit, Bd. 3715, Bl. 12, Niederschrift über die am 2. 2. 1948 bei der Generalstaatsanwaltschaft in Gera stattgefundene Besprechung.
} 
den Arbeitskräftemangels wurde namentlich der Uranbergbau als möglicher Einsatzort für Strafgefangene festgehalten, wobei den Gefangenen Straferlaß in Aussicht gestellt werden sollte, falls sie sich für mindestens ein Jahr verpflichteten. Damit wurde dem sächsischen Erzbergbau eine Sonderrolle zugewiesen, da die Strafgefangenen, die sich für diesen Arbeitseinsatz freiwillig meldeten, Sonderkonditionen erhielten, die in den Richtlinien vom 1. September 1947 ursprünglich nicht vorgesehen waren ${ }^{212}$. Die Besserstellung diente in erster Linie einem Ziel: der Gewinnung neuer Arbeitskräfte für die Wismut AG. In Thüringen mußte die Arbeitsverwaltung bei ihren Bemühungen, Strafgefangene für den Arbeitseinsatz zu gewinnen, einen Rückschlag hinnehmen, da im Zuge der am 18. März ausgesprochenen Amnestie ein Großteil von Gefangenen, die für die Aktion in Frage gekommen wären, nun nicht mehr zur Verfügung stand ${ }^{213}$.

Der Mobilisierung von Strafgefangenen für den Arbeitseinsatz waren letztlich enge Grenzen gesetzt, die mit der besonderen Lage der Gefangenen direkt zusammenhingen. Nachdem HVAS-Mitarbeiter einzelne Haftanstalten besucht hatten, reduzierte sich der Personenkreis drastisch. Während die Leichtbestraften mit Haftstrafen bis zu einem Jahr weiterhin zur Verfügung standen, wurden Gefängnisinsassen mit einer mehrjährigen Freiheitsstrafe aus dem Reformvorhaben herausgenommen: Wegen Fluchtgefahr erschien den Gefängnisleitungen, der DJV, aber auch der HVAS der Arbeitseinsatz außerhalb der Gefängnismauern als zu riskant ${ }^{214}$. Diese Bedenken galten offenbar auch gegenüber der Mehrzahl der Untersuchungshäftlinge. Nach Einschätzung der HVAS waren die Möglichkeiten noch begrenzt, innerhalb der Haftanstalten Arbeitsplätze bereitzustellen. So waren beispielsweise bei der Strafanstalt Coswig von insgesamt 524 einsitzenden Männern nur 87 in der Anstalt als Hausarbeiter (29 Gefangene), Handwerker (35) oder Korbmacher (23) beschäftigt worden, dagegen befanden sich 142 Gefängnisinsassen im Arbeitseinsatz außerhalb der Anstalt ${ }^{215}$. Die HVAS gab sich zuversichtlich, daß im Rahmen des Zweijahrplanes die Zahl der Arbeitsplätze innerhalb der Haftanstalten erheblich vergrößert werden könnte, ließ dabei jedoch die desolate Situation der öffentlichen Haushalte völlig unberücksichtigt. Die Schaffung einer entsprechenden Infrastruktur, die arbeitsmarktpolitischen und sicherheitspolitischen Überlegungen gerecht wurde, schien daher reines Wunschdenken zu sein. Bei der weiteren Planung des Arbeitseinsatzes von Strafgefangenen wurden die DWK-Hauptverwaltung Wirtschaftsplanung sowie die entsprechenden Abteilungen der Landesregierungen verstärkt einbezogen ${ }^{216}$. Darüber hinaus sollten in den Ländern Kommissionen gebildet werden, welche die verschiedenen Mög-

212 ThHStA, Land Thüringen, Ministerium für Wirtschaft und Arbeit, Bd. 3699, Bl. 158, Ministerium für Arbeit und Sozialwesen des Landes Thüringen am 10.2. 1948 an alle Ämter für Arbeit und Sozialfürsorge des Landes.

213 Ebenda, Bl. 159, Ministerium für Arbeit und Sozialwesen des Landes Thüringen am 26.6. 1948 an alle Ämter für Arbeit und Sozialfürsorge des Landes.

${ }^{214}$ BAB, DQ 2/2047, Bericht der HVAS-Abt. I b vom 19. 8. 1948 über die Besichtigung und Prüfung von sechs Strafanstalten (10.-13. 8. 1948), S. 1.

215 Ebenda, S. 2 f.

216 SächsHStA, Landesregierung Sachsen, Ministerium für Arbeit und Sozialfürsorge, Bd. 319, Protokoll der HVAS über Besprechung der HV Wirtschaftsplanung mit der HVAS und der DJV am 18. 11. 1948, S. 1 f. 
lichkeiten des Gefangeneneinsatzes in Strafanstalten oder in betrieblicher „Kolonnen-Arbeit" zu prüfen hatten ${ }^{217}$.

In der Folgezeit stellte sich immer mehr heraus, daß die Voraussetzungen für einen organisierten Arbeitseinsatz von Strafgefangenen im geplanten Ausmaß nicht gegeben waren. Die eingesetzten Kommissionen ${ }^{218}$, aber auch die Hauptverwaltungen Wirtschaftsplanung der Länder konnten ihrerseits keine Verbesserung der Situation herbeiführen ${ }^{219}$. Dies lag nicht nur an den allgemeinen Rahmenbedingungen, insbesondere an der fehlenden Bereitstellung von Geld- und Sachmitteln, sondern hatte auch immanente Gründe. Der flexible Einsatz von Arbeitskräften, den die Arbeitsämter - idealtypisch gesehen - am jeweiligen Bedarf ausrichten wollten, war letztlich undurchführbar bei Personen, die Straftaten begangen hatten und somit unter besonderer Obhut der Justizbehörden standen. Daher mußte sich die Diskussion über den Arbeitseinsatz von Gefangenen zwangsläufig auf diejenigen mit geringfügigen Vergehen und kurzen Haftstrafen konzentrieren.

Nachdem die Richtlinien über den Arbeitseinsatz am 1. September 1947 in Kraft getreten waren, mußten eine ganze Reihe von Detailfragen geklärt werden. Dazu gehörten nicht nur der Auf- und Ausbau entsprechender Arbeitsplätze innerhalb und außerhalb der Haftanstalten, sondern auch Fragen des Arbeitsschutzes und der Entlohnung. Eine Ausnahmestellung nahm dabei der Uranbergbau ein, der sehr viel früher als andere Wirtschaftsbranchen dazu übergegangen war, angesichts des Arbeitskräftemangels Anreize für den freiwilligen Wechsel zur Wismut AG zu schaffen. Davon profitierten in gewisser Weise auch die Strafgefangenen, die zur Arbeit eingesetzt wurden, da sie ebenfalls in den Genuß der materiellen Bevorzugung kamen. Ansonsten gab es keine allgemein gültigen $\mathrm{Be}-$ stimmungen zur Arbeitsentlohnung - dies blieb den Betrieben überlassen 220. So erklärt sich auch die Spannbreite der Vergütung: Während die Mehrzahl der Unternehmen nur einen eher symbolischen Betrag überwies, zahlten etwa in Sachsen bei einigen "guten und fortschrittlichen" Strafanstalten die Betriebe den regulären Tariflohn an das jeweilige Gefängnis. Diese zogen wiederum einen Teil für die eigenen Aufwendungen ab und überwiesen den restlichen Lohn auf ein Konto des Gefangenen, über das dieser erst nach Ablauf seiner Haftzeit verfügen konnte. Der sowjetischen Besatzungsmacht, die sich bisher auffallend zurückgehalten hatte, ging diese Entwicklung entschieden zu weit. Zuvor hatten Vertreter der SMAD bereits grundsätzliche Bedenken gegenüber der Bewährungsarbeit geäuBert, wobei vor allem der Reformaspekt - Arbeit als Instrument zur langfristigen Eingliederung in die Gesellschaft - dem sowjetischen Rechtsdenken einigermaßen fremd war. Die Rechtsabteilung der SMA Brandenburg hielt beispielsweise die Regelung, daß Bewährungsarbeiter grundsätzlich freie Arbeiter sind und den ortsüblichen Tariflohn erhalten, für "unangebracht" ${ }^{\text {"21 }}$. Der Herausgabe der

217 Ebenda, S. 1. Vgl. ThHStA, Land Thüringen, Ministerium für Wirtschaft und Arbeit, Bd. 3715, Bl. 119-125, Protokoll über die 1. Landesausschuß-Sitzung am 10.12.1948.

218 BAB, DQ 2/2480, Aktenvermerk der HVAS-Abt. I a vom 4. 3. 1949.

219 BAB, DQ 2/2022, Aktenvermerk der HVAS-Abt. I a vom 26. 2. 1949.

220 Ebenda.

$221 \mathrm{BAB}, \mathrm{DQ} 2 / 2480$, DJV am 16. 5. 1949 an HVAS. 
Richtlinien vom 1. September 1947 hatte sich die SMAD nicht in den Weg gestellt, bei der Festlegung der Lohnsätze für Strafgefangene im Arbeitseinsatz intervenierten jedoch einzelne SMA-Abteilungen ${ }^{222}$. Sowohl DJV als auch HVAS betonten den Erziehungsgedanken bei der Bewährungsarbeit und erklärten, daß der Standpunkt der SMA Brandenburg eine wesentliche inhaltliche Änderung der gesetzlichen Bestimmungen mit sich bringen würde: Mit dem geforderten partiellen Lohnabzug wäre der Charakter einer Strafe nicht genommen, „wie es mit den Richtlinien geplant“ war223. Und weiter: „Es würde sich dann keinesfalls mehr um einen vollen Strafaufschub zur Bewährungsarbeit handeln, bei der der Erziehungsgedanke im Vordergrund steht. Damit würde auch dem Bewährungsarbeiter, bei dem eine günstige soziale Prognose vorliegt, nicht die soziale Deklassierung erspart bleiben." Die Zentralverwaltungen in Berlin erhielten Unterstützung von seiten des FDGB-Bundesvorstandes, der sich ebenfalls gegen den Vorstoß der SMA wandte 224 . Nachdem sich auch noch das Zentralsekretariat der SED in gleicher Weise geäußert hatte, bat der DJV-Präsident Max Fechner das brandenburgische Justizministerium, den Bewährungsarbeitern den in den Richtlinien vorgesehenen tariflichen Arbeitslohn weiter zu zahlen ${ }^{225}$.

Mitte des Jahres 1949 legte die HVAS eine Statistik über den Arbeitseinsatz von Strafgefangenen vor, die zumindest einige Tendenzen deutlich machte und eine Gewichtung dieses Instruments für die Arbeitskräftelenkung generell zuließ226. Auf den ersten Blick handelte es sich um eine relativ große Personengruppe, die seit Inkrafttreten der Richtlinien eingesetzt worden war: Insgesamt registrierte die Arbeitsverwaltung 14858 Bewährungsarbeiter, von denen sich der größte Teil in Brandenburg befand (6362); es folgten Thüringen (3460), Sachsen-Anhalt (3109), Sachsen (1127) und Mecklenburg (etwa 800). Zum zweiten fiel auf, daß die Widerrufquote infolge von Arbeitsbummelei und schlechter Arbeitsleistung niedrig lag (4,5 Prozent). Ein Blick auf die Gesamtzahl der Bewährungsarbeiter, die am 1. Juni 1949 im Arbeitseinsatz waren (2475 Personen, wobei aus Sachsen die entsprechenden Angaben fehlten), verdeutlicht allerdings die hohe Fluktuation und damit den geringen Nutzen aus Sicht der HVAS. Da in erster Linie die Leichtbestraften mit Haftstrafen unter einem Jahr zum Einsatz kamen, blieb deren Verweildauer auf den zugewiesenen Arbeitsplätzen gering: Sie schieden oftmals nach wenigen Monaten wieder aus.

Der Arbeitseinsatz von Gefangenen innerhalb der Strafanstalten blieb weiterhin problematisch, da sich an der technischen Ausstattung (Maschinen) sowie an der Belieferung mit Rohstoffen wenig geändert hatte 227 . Die Rechtsabteilung der SMAD drängte im Laufe des Sommers 1949 erneut auf eine bessere Ausschöpfung des Arbeitskräftepotentials in den Haftanstalten. Aus diesem Grunde wies die DJV die Landesjustizministerien am 18. August 1949 an, die Zusammenarbeit mit

\footnotetext{
222 Die SMA Brandenburg plädierte dafür, bei Bewährungsarbeitern grundsätzlich die Hälfte des Lohnes an die Justizverwaltung abzuführen. Vgl. ebenda.

${ }^{223}$ BAB, DQ 2/2480, HVAS (Herm) am 27. 5. 1949 an die DJV.

224 SAPMO, DY 34, 18/-/530, FDGB-Bundesvorstand am 8.6. 1949 an die DJV.

225 Ebenda, Schreiben der DJV (Fechner) vom 25.6. 1949 an das Ministerium der Justiz des Landes Brandenburg.

226 BAB, DQ 2/2022, Statistik zum Bewährungseinsatz (Stand: 1. 6. 1949).

${ }^{227}$ Ebenda, Litke am 16. 8. 1949 an die SMAD-Abt. Arbeitskraft (Morenow).
} 
den Ende 1948 gebildeten Kommissionen wieder aufzunehmen. Um langfristig den Arbeitseinsatz von Strafgefangenen zu verstärken, sollten genaue Erhebungen durchgeführt werden über die Zahl der Betriebe in den einzelnen Ländern, in denen Arbeitsplätze für Gefangene angeboten werden könnten. Außerdem hatten die Landesverwaltungen den dabei entstehenden Bedarf an Rohstoffen und Maschinen zu ermitteln. Gleichzeitig legte die DJV einen Verordnungsentwurf über die „Einplanung des Arbeitspotentials der Strafanstalten“ vor und leitete diesen der HVAS sowie der Deutschen Verwaltung des Innern (DVdI) zu228. Der Entwurf verpflichtete die Strafanstalten, den zuständigen Arbeitsämtern regelmäßig über die berufliche Qualifikation der einsitzenden Gefangenen zu berichten. Für die Bereitstellung eines entsprechenden Arbeitsplatzangebotes waren demzufolge die Landesarbeitsämter verantwortlich. Der Verordnungsentwurf der DJV sah außerdem eine stärkere Einbindung der Betriebe vor: So konnten die Landesämter für Arbeit und Sozialfürsorge „bestimmten Betrieben Auflagen zur Verwendung der Arbeitskraft Gefangener" machen. Größere Unternehmen mit mehr als 100 Beschäftigten sollten sogar generell verpflichtet werden, „eine bestimmte Zahl von Arbeitsplätzen, jedoch nicht mehr als 5\% der Gesamtzahl“ für den Einsatz von Bewährungsarbeitern bereitzustellen. Inwieweit die DJV dieses Vorhaben realisieren konnte, muß offen bleiben. Fest steht zumindest, daß ab September 1949 die Lenkung des Einsatzes von Bewährungsarbeitern ausschließlich den Arbeitsministerien der Länder übertragen wurde. Diese legten mitunter für die einzelnen Arbeitsamtsbezirke die jeweils in Frage kommenden Betriebe für den Arbeitseinsatz fest ${ }^{229}$. Obwohl der verstärkte Arbeitseinsatz von Strafgefangenen aufgrund der erwähnten wirtschaftlichen und technischen Schwierigkeiten erheblich eingeschränkt war, weigerte sich die HVAS, den Reformgedanken der Bewährungsarbeit vollständig fallenzulassen ${ }^{230}$.

228 $\mathrm{BAB}, \mathrm{DQ} 2 / 2063$.

$229 \mathrm{BAB}, \mathrm{DQ} 2 / 1870$, Ministerium für Arbeit und Sozialwesen der Landesregierung Sachsen-Anhalt am 22. 9. 1949 an alle Ämter für Arbeit und Sozialfürsorge.

230 Ein entsprechender Vorschlag kam offensichtlich vom thüringischen Arbeitsministerium. Vgl. BAB, DQ 2/2022, HVAS (Donau) am 24. 10. 1949 an das Ministerium für Arbeit und Sozialwesen der Landesregierung Thüringen. 